\title{
A Typology of Multidimensional Adjectives
}

\author{
Galit W. Sassoon, \\ ILLC, University of Amsterdam*
}

This paper presents corpus-based evidence for a typology of multidimensional adjectives, like for example, healthy and sick. The interpretation of the latter is sensitive to multiple dimensions, such as blood pressure, pulse, sugar, cancer, etc. The study investigated the frequency of exception phrases, which operate on an implicit universal quantifier over adjectival dimensions, as in healthy, except for a slight cold, and not sick, except for high cholesterol. On the emerging typology, adjectives classify by the way their dimensions are glued together to create a single, uniform interpretation. The default interpretation of adjectives such as healthy involves implicit universal quantification over dimensions (dimension conjunction), while that of adjectives such as sick involves existential quantification (dimension disjunction). In adjectives like intelligent, the force of quantification over dimensions is context relative. Moreover, the paper presents support to the hypotheses that antonym polarity and modifier distribution guide our choice of quantifiers over dimensions in different adjectives. Thus, this research sheds new light on the nature of negative antonymy in multidimensional adjectives, and on the distribution of degree modifiers and exception phrases among multidimensional antonyms. Finally, it raises new questions pertaining to multidimensional comparisons.

\section{Introduction}

\subsection{Predicate typology based on strategies of dimension integration}

Adjectives, such as tall and bald are often called dimensional for their interpretation is tightly dependent on entity values along a scalar dimension, e.g., height for tall and hair for bald. Other adjectives are called multidimensional (Kamp 1975; Klein 1980), since they are associated with multiple dimensions. Typical examples of multidimensionality include adjectives such as similar, identical, typical, normal, good, clever, talented, happy, beautiful, human, and healthy. An adjective like healthy, for example, may be associated with many different dimensions simultaneously, such as blood pressure, pulse, cholesterol, cancer, lung functions, sugar, fever, flu, pneumonia, chickenpox, and so forth. One can be healthy with respect to blood pressure, but not with respect to cholesterol. Likewise, two entities may be identical or similar with respect to color, but not size. Conversely, an adjective such as long falls short of being truly multidimensional despite its having both a temporal and a spatial dimension, as it is

\footnotetext{
*The research for this paper began thanks to the Orgler scholarship for PhD students, Tel Aviv University (2006-7), continued thanks to the Pratt scholarship, Ben Gurion University of the Negev (2007-8) and was completed thanks to funding of the project 'On vagueness - and how to be precise enough' by the Netherlands Organization for Scientific Research (NWO 360-20-201). I warmly thank Nirit Kadmon, Fred Landman, Robert van Rooij, Frank Veltman, and the audiences of ESPP 16 (2008), IATL 25 (2009) and the linguistic colloquiums of Jerusalem, Tel Aviv, and Bee'r-Sheva for their most helpful comments. Special thanks to Alice Ter Meulen, Elena Tribushinina, Dorit Ben-Shalom, Edit Doron, Danny Fox, Micha Breakstone, Ivy Sichel, Louise McNally, Bart Geurts, François Recannati, Yael Greenberg, and Adar Weidman, for insightful comments. Needless to say, any mistakes are solely mine.
} 
interpreted only relative to one of these dimensions in each context, never relative to both simultaneously. Thus, not all word senses admit multiple dimensions.

Adjectives with multiple dimensions have a dimension argument, which either can be saturated as in (1a-b), or bound as in (2a-b). On dimensional adjectives do not, as illustrated in $(1 \mathrm{c}, \mathrm{d})$ and $(2 \mathrm{c}, \mathrm{d})$.

(1) a. The boxes are identical except for their size.

b. Sam is intelligent/good in mathematics.

c. \#The wedding is long with respect to temporal duration (but not with respect to space).

d. \#The table is long with respect to temporal duration (but not space).

(2) a. The boxes are identical in \{all, most, three, some $\}$ respects.

b. Dan is $\{$ generally, otherwise, all in all $\}$ healthy.

c. \#The table is long in $\{$ all, most, three, some $\}$ respects.

d. \#The wedding/table is $\{$ generally, otherwise, all in all $\}$ long.

Empirical research shows that categorization under color adjectives is based on dimensions such as hue and saturation. However, we normally do not use color adjectives in constructions involving reference to- or quantification over dimensions, as the oddness of ?red in every respect except for hue illustrates. Hence, grammatically, color adjectives pattern with the one-dimensional adjectives tall, long, heavy, and so on.

Additionally, examples $(3 a, b)$ illustrate that noun dimensions do not typically function as arguments.

(3) a. \#The wedding with respect to the food, the way people were dressed, the church \} took place yesterday.

b. \#The wedding in $\{$ all, most, three, some $\}$ respects took place yesterday.

We do not tend to describe an entity as a bird in every respect except for flying, or a chair except in the seat sense. Such statements are neither uninterpretable, nor flat-out ungrammatical, but speakers generally agree that they are marked and unusual in comparison with similar adjectival statements. Exceptions to this generalization typically include nouns that are directly related to an adjective semantically and/or morphologically, like nominalizations, as in similarity with respect to color, and thuman evaluative nouns, as in a \{genius, idiot \} except with respect to mathematics.

When speakers use bare forms of adjectives, as in Dan is healthy and Bill is similar to Mary, they presuppose that their addresses can select contextually relevant respects. The dimension argument is implicitly saturated or bound. Many questions remain open. Which operations bind the dimensions of the adjectives in these examples? Are they bound by logical operations, as in healthy in all/some respects, or by nonlogical operations, as in, for example, healthy on average? Do different adjectives default different binding operations (henceforth - 'dimension-integration' operations)? For example, intuitively, healthy and sick seem to default interpretations equivalent to healthy in every respect vs. sick in some respect. How do speakers learn default dimension-integration operations of adjectives, if such exist, from patterns of usage? 
Finally, are the same dimension-integration defaults equally available for adjectives and nouns?

Extensively supported concept-theories, including among others Prototype and Exemplar theories, analyze the concepts underlying nouns by means of a similarity structure; for a lengthy review of theories and experimental support, the reader is referred to Murphy (2002: ch. 3) and Hampton (1995, 1998). Consider, for example, a psychological analysis of nouns like bird; experiments suggest that the conceptual structure of this noun includes a rich cluster of dimensions, $\mathrm{F}$ (bird), which is called the prototype or summary representation of the concept. It include features like 'birdgenotype', 'bird descendant', 'can interbreed with birds', or merely 'winged', 'feathered' and 'small'. Each dimension $\mathrm{F}$ in $\mathrm{F}$ (bird) has an attention weight $\mathrm{W}_{\mathrm{F}}$. For example, $\mathrm{W}_{\text {size }}$ tells us how important size is in discriminating birds from non-birds. In addition, the conceptual structure of bird includes an ideal value on each dimension; for example, $\operatorname{deg}($ bird,size), represents the ideal size for birds. The distance of an entity $\mathrm{x}$ from the ideal size for birds equals the difference between $x$ 's size and the ideal bird size: $\mid \operatorname{deg}(\mathrm{x}$, size $)-\operatorname{deg}($ bird,size $) \mid$.

Finally, a similarity structure includes a mapping of entities $\mathrm{x}$ to degrees, $\operatorname{deg}(\mathrm{x}, \mathrm{bird})$, representing their similarity to birds, the extent to which their values on the dimensions match the ideal values for birds. The average distance of $\mathrm{x}$ from the prototpe of bird, represented using an arithmetic mean, is the sum of x's weighted distances in all of the dimensions: $\mathrm{D}(\mathrm{x}$, bird $)=\Sigma_{\mathrm{F}_{\mathrm{i}} \in \mathrm{F}(\mathrm{bird})} \mathrm{W}_{\mathrm{i}}\left|\operatorname{deg}\left(\mathrm{x}, \mathrm{F}_{\mathrm{i}}\right)-\operatorname{deg}\left(\operatorname{bird}, \mathrm{F}_{\mathrm{i}}\right)\right|$. The degree of similarity of $\mathrm{x}$ to the protoype of bird, $\operatorname{deg}(\mathrm{x}, \mathrm{bird})$, is inversely related to $\mathrm{x}$ 's distance from the prototype, $\mathrm{D}$ (x,bird). Entities are classified as birds iff their similarity to birds is greater than some threshold, or greater than their similarity to contrasting categories such as mammals and reptiles. In certain cases, categorization is based on similarity to an exemplar - the prototype of a sub category of birds - robins, chickens, ducks, and so on, or similarity to encoded instances of the category. The same basic mechanism represents all these cases. Instances provide sets of dimensions and ideal values which are their own values on salient dimensions.

Hence, on these theories, for an entity $\mathrm{x}$ to count as a bird, $\mathrm{x}$ need not sufficiently resemble a bird, or a bird exemplar, along ALL of the relevant dimensions, or along ONE relevant dimension. Rather, the overall distance of $\mathrm{x}$ from the ideal bird size, the ideal bird form, and so forth, should be small enough for $\mathrm{x}$ to classify as a bird. The distances of $\mathrm{x}$ from the prototypical values in the different bird dimensions integrate into a unique degree in the given noun by means of averaging operations, like weightedsums, as in the example above, and weighted-products (Hampton 1995). ${ }^{1}$ The name

\footnotetext{
${ }^{1}$ The rang of dimension integration operations employed by similarity-based analyses of linguistic concepts can be expressed by means of a general formula, which is known in mathematics under the name 'the generalized weighted-mean function,' (Weidman 1993; Sassoon 2007: 94). Formally, the generalized weighted-mean $f(x, D I M, r)$ of an entity $x$ in a set DIM of dimensional measurements $f_{1} \ldots . f_{n}$ (functions from entities to degrees within the real interval $[0,1]$ ) with respective weights $\mathrm{w}_{1} \ldots \mathrm{w}_{\mathrm{n}}$ (positive real numbers that sum up to 1), given a real constant $r \neq 0$, is $\mathrm{f}(\mathrm{x}, \mathrm{DIM}, \mathrm{r})=\left(\sum_{\mathrm{fi} \in \mathrm{DIM}}: \mathrm{w}_{\mathrm{i}} \mathrm{f}_{\mathrm{i}}(\mathrm{x})^{\mathrm{r}}\right)^{1 / \mathrm{r}}$. For $\mathrm{r}=1$, this formula yields an arithmetic weighted sum, for $\mathrm{r}=2$, it yields an Euclidian sum, and so on. The theories and generalized formula are presented and explained in detail in Murphy (2002: 67-68). However, the explicit classification of these theories as 'mean-based', by resort to the name of the generalized formula, is by no means widespread in psychology. The present paper highlights this name as it aims to explore the contrast between 'mean-based' operations of dimension binding and logical 'quantificational' operations.
} 
similarity highlights reference to ideal values, but the defining characteristic binding the multiple and variable accounts within the similarity approach is, rather, the rejection of logical dimension integration, in favor of 'non logical' functions such as weighted sums and products (averaging). In fact, the similarity based approach came into being as a response to 'the classical theory', namely a family of accounts that are bound together by the use of logical dimension-integration operations, such as conjunctions and disjunctions (Lakkof 1987: ch. 1; Murphy 2002: ch. 1).

Cognitive-linguistic theories incorporate the psychological similarity structures into the lexical semantic representations of the meaning of words (Lakoff, 1987). However, typically, these theories do not address distinctions between nouns and multidimensional adjectives with respect to the way their dimensions are combined. Consider, for example, a context in which health is measured by the results of medical blood tests for the three dimensions blood pressure, pulse and sugar (a measure of diabetics), or alternatively, by medical blood-tests for the three dimensions pneumonia, flu, and chickenpox. Imagine that Dan has the maximal degree in two of these dimensions, but he is not within the norm in the third. Conversely, imagine that in all of these dimensions, Sam's levels are within the normative range, but they are the lowest possible, so Dan's mean on the dimensions is higher than Sam's is. Now consult your intuitions. Is Dan healthy? Why? Is Sam healthy? Why?

Dan's mean on the dimensions is higher than Sam's is. Nonetheless, intuitively, in this scenario, Sam is strictly speaking healthy, but Dan is not, because Sam, but not Dan, reaches the norm in all of the contextually relevant respects. Because of that, intuitively, Sam is healthier than Dan (for survey results along these lines see Sassoon 2011a). This judgment suggests that we do not compare directly Sam's and Dan's means on the dimensions. Had we done that, we would have judged Dan to be healthier than Sam. Rather, we fix negative and positive denotations for healthy, based on dimension intersection. For the positive denotation, we select entities that reach the standard in all of the dimensions. For the negative denotation, we select entities that do not reach the standard in all of the dimensions. Only then (if at all), do we allow comparisons between denotation members (and between non-members), based on averaged degrees.

These observations suggest that there exists a systematic semantic difference between paradigmatic nouns like bird and table, and paradigmatic multidimensional adjectives. While classification in nominal denotations is, if concept theories are correct, meanbased, as stated in (4a), the situation may be different in adjectives, as proposed in (4bc); the latter are the main proposals, which this paper aims to put to empirical test.

(4) Hypothesis set 1: A typology based on strategies of dimension integration

a. Nouns are similarity-based. An entity is classified under a count noun iff the weighted sum of its similarity degrees to the ideal values in the dimensions of the noun (or one of its exemplars) exceeds the membership standard (Murphy, 2002, ch. 3).

b. Adjectives like healthy are by default conjunctive. Entities are required to reach the standard in all of their dimensions.

c. Adjectives like sick are by default disjunctive. Entities are required to reach the standard in but one of their dimensions. 
d. Adjectives like intelligent are indeterminate. Pragmatics determines whether e.g., being intelligent in but one dimension (say, mathematics) suffices to count as intelligent, or every contextually relevant intelligence measure must be considered.

To illustrate, the difference between logical and non-logical (similarity-based) dimension integration in multidimensional adjectives is as follows. If healthy/sick are similarity based, for $x$ to count as healthy/sick, x's degree of health with respect to, e.g., blood pressure (times the weight of this dimension), plus x's degree of health with respect to cholesterol (times the weight of this dimension), plus x's degree of health with respect to lung functions (times...), and so on, has to exceed/not to exceed the threshold for membership in the category. By contrast, if healthy/sick are based on logical rules, for $\mathrm{x}$ to count as healthy/sick, it has to be/not to be the case that x's degree with respect to blood pressure exceeds the normative threshold for healthy blood pressure, AND x's degree with respect to cholesterol exceeds the normative threshold for healthy cholesterol, AND x's degree with respect to lung functions exceeds threshold for lung functions, AND...so forth. ${ }^{2}$ This paper presents preliminary corpus evidence suggesting that multidimensional adjectives are significantly more likely than nouns like bird to select the latter among these two types of dimension integration. Hence, the results of the presented study support the hypothesized typology of conjunctive and disjunctive adjectives in (4b-c).

To summarize, on top of questions concerning the way adjectival semantics is affected by each scalar dimension, multidimensional adjectives pose difficult questions concerning the way a set of contextually relevant dimensions may be selected and the way information regarding different dimensions in such a set may be incorporated within context to create a single uniform interpretation for a given adjective. While the semantics of one dimensional adjectives forms a popular topic of research, issues pertaining to the more complicated semantics of multidimensional adjectives are hardly investigated within formal semantics. ${ }^{3}$

This paper discusses some basic observations, based on intuitive judgments and a corpus study. This study does not test generalizations derived based on some existing explicit semantic mechanism; rather, it aims to highlight data-driven, descriptive generalizations. This is rather uncommon in natural language semantics, but quite typical of quantitative analyses. Based on the study reported in this paper, some general ideas about possible theoretical accounts arise, which may form a basis for future work on a formal theory of multidimensionality. Hence, this study forms a preliminary stage in the research of the topic; it sheds light on some pieces of the puzzle pertaining to what adjectives do and how they do that, for future research to reveal how these, as well as additional as yet missing pieces, should be put together.

\footnotetext{
${ }^{2}$ Notice that the question is NOT whether the standard for a given dimension is based on the average degree of the entire population on that dimension or not (cf. Kennedy 2007), but rather whether the sum of different dimensional degrees is compared to a standard, or alternatively, each degree is compared to its own standard, such that all of the dimensions contribute categorization criteria.

${ }^{3}$ Also within cognitive psychology and psycholinguistics, the study of such adjectives generally lags behind that of nouns, verbs, and adjectives of color or spatial distance (Damon et al 2006: 315).
} 


\subsection{A new method to explore concepts and accommodation of implicit operators}

The context-dependency of the adjectival dimensions makes it difficult to support or refute hypotheses about dimension integration experimentally. Consider, for instance, the conjunctive dimension-integration hypothesis in (4b). One way to test it is to design a questionnaire to assess classification data in adjectives and their dimensions. This questionnaire will need to control each participant's dimension selection completely, in order to say whether participants in fact treat all of the dimensions they select for healthy as categorization criteria (as the proposal in (4b) predicts), or not (counter the proposal's prediction).

A main difficulty with this direction of investigation is that quantification in natural languages is contextually restricted. Thus, in everyday use, one can have high blood pressure, yet check 'healthy' on medical questionnaires. This is possible in contexts in which blood pressure does not count as a relevant dimension. Significantly, quantification over adjectival respects is by no means special in admitting context restrictions, as observed by Lewis (1979) and von Fintel (1994), among many others. For example, normally, utterances of statements such as everybody came to the party do not convey that everybody in the universe, the state or the city came. Nor is it necessary that everybody we know has been there; what the statement conveys is that everybody that counts came. Similarly, when we say that the Netherlands is flat, what we are saying is that it has no bumps, except for those that we ignore.

Some contexts require high standards of precision meaning that it is more difficult to ignore entities on the basis that they count as unimportant or irrelevant; e.g. normally, when one is healthy in every respect except for a slight cold, one can be loosely considered healthy. However, in the context of a pre-surgery medical examination, ALL dimensions, even unimportant ones, count. One is not strictly speaking healthy if one has a slight cold; hence, one would not check 'healthy' upon filling a medical questionnaire in such a context. Rather, intuitively, we consider entities that satisfy one dimension of sick - have one disease or other - to be sick, as long as that dimension counts as contextually relevant, and is therefore part of the domain of quantification of the existential quantifier that binds the dimensions of sick.

Instead of designing a questionnaire that addresses the difficulties context restrictions pose, the present paper takes on a different direction of investigation. The focus of this investigation is the pattern of usage of one marker of universal quantification - the exception phrase except - with different adjectives. The method is based on the fact that exception phrases are compatible with universal quantifiers such as every and no, but not with existential ones, as the contrast in felicity between $(5 \mathrm{a}, \mathrm{b})$ and $(5 \mathrm{c})$ illustrates (for additional data and theoretical discussion see von Fintel, 1993, 1994; Hoeksema 1995; Moltmann 1995; Fox and Hackl 2006). ${ }^{4}$

(5) a. Everyone is happy except for Dan

b. No one is happy except for Dan

c. \# Someone is happy except for Dan

\footnotetext{
${ }^{4}$ Note that $(5 \mathrm{c})$ is infelicitous, except in an alternative, 'in addition to' interpretation, whereby someone is happy in addition to Dan. An interpretation whereby Dan is presumably not happy is unavailable here. The 'in addition to' interpretation is not salient for many speakers, who reject $(5 \mathrm{c})$ altogether.
} 
Exception phrases can operate on universal quantifiers over adjectival dimensions, as in healthy in every respect except for a slight cold. Importantly, they can do so also if the quantifier is implicit, as in healthy except for a slight cold, as long as the adjective's truthful application is compatible with the requirement that ALL (or NONE) of the properties corresponding to its different dimensions be true of its argument. Therefore, exception phrases can reveal the force of the operations that bind the dimensions of multidimensional adjectives occurring bare, as in Dan is healthy.

If the dimensions of a bare adjective combine through a conjunctive strategy, i.e. via an implicit universal quantifier as stated in (4b), exception phrases are expected to cooccur with the adjective and operate on the implicit universal quantifier over its dimensions, as illustrated in (6). In contrast, if the dimensions combine through a disjunctive strategy, i.e. via an implicit existential quantifier as stated in (4c), exception phrases are expected not to operate on the implicit quantifier associated with the bare adjective. In the case of healthy and sick, these predictions are supported by intuitive judgments, as the felicity contrast in $(7 \mathrm{a}, \mathrm{b})$ illustrates.

(6) $[[\text { Dan is healthy except wrt blood pressure }]]_{\mathrm{c}}=1$ iff $\forall \mathrm{Q} \in(\mathrm{DIM}$ (healthy,c) $-\{$ (healthy wrt) blood pressure $\})$ : [[Dan is $\mathrm{Q}]]_{\mathrm{c}}=1$ where $\operatorname{DIM}(\mathrm{P}, \mathrm{c})$ is a set of predicates, $\mathrm{P}$ 's dimensions in context $\mathrm{c}$ (Dan is healthy wrt all dimensions except bp in context c)

(7) a. Dan is healthy, except for high blood pressure b.\#Dan is sick, except for blood pressure

Furthermore, negated universals are existential, and vice versa, as illustrated in (8):

$\begin{aligned} \text { (8) a. healthy } & \Leftrightarrow \text { healthy in every respect iff } \\ \text { not-healthy } & \Leftrightarrow \text { 'not-healthy' in some respect } \\ \text { b. sick } & \Leftrightarrow \text { sick in some respect } \\ \text { not-sick } & \Leftrightarrow \text { sick in no respect }\end{aligned}$

Hence, exception phrases are expected to combine with negated disjunctive adjectives, as in (9), but not with negated conjunctive adjectives. Again, these predictions are supported by intuitive judgments, as the felicity contrast in $(10 \mathrm{a}, \mathrm{b})$ illustrates. ${ }^{5}$

(9) $[[\text { Dan is not sick except wrt blood pressure }]]_{\mathrm{c}}=1$ iff

\footnotetext{
${ }^{5}$ Crucially, the distribution of exception phrases is restricted to 'positive' (upward entailing) contexts (von Fintel, 1993, 1994; Fox and Hackl 2006 and references within), meaning that, indeed, no exception phrases are expected to occur with conjunctive adjectives when negated, especially not in written corpora. Thus, the reading of \#Dan is not healthy (in every respect) except bp whereby negation out scopes the implicit universal quantifier (as in "it is not the case that: Dan is healthy in all respects except bp") is generally not available. I am indebted to Danny Fox for these observations. Here are two very rare examples of this sort (Coca 2010); Notice that (iia) can only convey (iib) for vomiting cannot be healthy.

(i) It is fallacious to claim that the U.S. health care system is pretty good except that it costs more.

(ii) a. ... the infant was not healthy except for the regurgitation or vomiting b. In addition to regurgitation or vomiting, the infant was not healthy also in other respects. While (iia) is a naturally occuring example, native speakers tend to judge it as utterly unatural.
} 
$\neg \exists \mathrm{Q} \in(\mathrm{DIM}($ sick,c $)-\{$ (sick wrt) blood pressure $\}):[[\mathrm{Dan} \text { is } \mathrm{Q}]]_{\mathrm{c}}=1$ iff:

$\forall \mathrm{Q} \in(\mathrm{DIM}$ (sick,c) $-\{$ (sick wrt) blood pressure $\}):[[\mathrm{Dan} \text { is } \mathrm{Q}]]_{\mathrm{c}} \neq 1$

(Dan is sick wrt no dimension except bp in context c)

(10) a. Dan is not sick, except for high blood pressure

b.\# Dan is not healthy, except for normative blood pressure

Finally, if the dimensions of a bare predicate combine through similarity operations such as averaging, as concept-theories have it with nouns, no dimension set readings are expected to occur with exception phrases. Intuitive judgments tend to support these predictions, as the following infelicity judgments illustrate. Both (11a) and (11b) are intuitively marked - they are less natural than the adjectival examples in (7a) and (10a).

(11) a. \#Tweety is a bird, except \{with respect to flying, for her size

b. \#Tweety is not a bird, except \{with respect to flying, for her size $\}$

Hence, we can test quantitatively the predictions of the proposal that adjectival dimensions are integrated through logical, Boolean operations (conjunction and disjunction, or equivalently - universal and existential quantification), rather than through similarity (averaging), by searching for exception phrases preceded by an predicate and checking whether they can operate over an implicit quantifier over its dimensions.

An essential element for the success of such a study lies in a careful control of other roles logical operations might play in the interpretation of adjectives. The next section discusses the role of universal and existential quantifiers in determining the membership standard of different adjectives, as well as the role of negation in determining the polarity of adjectival antonyms. It presents the hypothesis that standard type and antonym polarity reveal whether dimension integration is by default conjunctive or disjunctive. They function as cues for determining the force of implicit quantifiers over dimensions in bare occurrences of multidimensional adjectives.

\subsection{Logical operations in the interpretation of adjectives}

\subsubsection{Antonym polarity as an indicator of dimension-integration strategy}

On a negation theory of antonymy, negative antonyms are negations of their positive counterparts. For example, on the syntactic negation theory of antonymy (Heim 2006, 2008; Büring, 2008), instead of being specified in the lexicon, antonyms are formed by a predicate negation operator little, hidden in their logical form. For example, short is decomposed into a multiword expression equivalent to little tall.

A negation theory of antonymy predicts that the force of quantification over dimensions will vary systematically in antonym pairs because of compositional processes, i.e. the application of a negation operator in negative antonyms. For example, if to count as healthy one has to be maximally/much healthy in every dimension and sick is the negation of healthy, then to count as sick one should count as not-healthy, i.e. not maximally/much healthy in at least one dimension. Similarly, if to count as familiar it suffices that an object be minimally familiar in but one respect, then to count as 
unfamiliar an object should count as not at all familiar in every respect. This is a minimal requirement in the sense that relaxing it amounts to allowing an overlap between the denotations of the two antonyms. Hence, hypothesis 2 derives from a negation analysis of antonymy:

\section{(12) Hypothesis 2: Antonymy as a predictive factor}

Antonyms differ with respect to the default force of the quantifier binding their dimensions: A is conjunctive if and only if A's antonym is disjunctive.

Formally, if healthy is equivalent to $\lambda \mathrm{x} . \forall \mathrm{Q} \in \mathrm{DIM}$ (healthy), healthy-wrt(x,Q), sick as the logical negation of healthy should be equivalent to $\lambda \mathrm{x} . \neg \forall \mathrm{Q} \in \mathrm{DIM}$ (healthy): healthy$\operatorname{wrt}(\mathrm{x}, \mathrm{Q})$, which reduces to $\lambda \mathrm{x} . \exists \mathrm{Q} \in \mathrm{DIM}$ (healthy): $\neg$ healthy-wrt(x,Q)).

Similar hypotheses can be formulated for other morphologically or syntactically complex expressions with multidimensional adjectives. Consider, for example, the comparative morpheme more or -er (as in taller). Abstracting away from irrelevant details, the standard interpretation of these morphemes is equivalent to a function from a the interpretation of a predicate $\mathrm{P}$, and two entities $\mathrm{x}$ and $\mathrm{y}$, to truth iff for some degree on P's scale, $\mathrm{x}$ is $\mathrm{P}$ to at least that degree, but $\mathrm{y}$ is not; i.e., $\mathrm{x}$ is Per than $\mathrm{y}$ iff $\mathrm{x}$ 's maximal degree in $\mathrm{P}$ is higher than y's (Kennedy 1999). Considering this interpretation, it is easy to see that the comparative morpheme can only select as an argument one predicate interpretation - one dimensional scale - at a time. Therefore, an important open question concerns comparatives derived from multidimensional adjectives; e.g., given that $\mathrm{x}$ can be healthier than y in one respect, but not in another, what does the bare comparative form healthier mean? Similar issues arise concerning, for example, healthiest, the least beautiful, very healthy, too healthy, and so on and so forth.

If compositionality plays a systematic role, we may expect that the dimensions of, e.g., comparative adjectives be integrated via the default operation of the adjectives they derive from; according to this hypothesis, since the comparative morpheme -er can only select one dimension at a time, by default, healthier is interpreted as conveying "healthier in every respect", $\lambda x . \forall Q \in \operatorname{DIM}$ (healthy): er(healthy-wrt(x,Q)).

\section{(13) Hypothesis 3: Compositionality}

The interpretation of expressions derived from adjectives (e.g., derived comparatives and superlatives) is mediated by the default quantification of the adjectives from which they are derived.

Here again, it is important to remember the role of context restrictions. On a scenario whereby a man has high blood pressure, while his dying wife has normal blood pressure, intuitively, the husband is healthier despite of him doing less well in one respect. This intuition is consistent with a quantificational analysis, granting that blood pressure does not count as a relevant dimension in the given context (Lewis 1979, von Fintel 1994). Only dimensions that affect the protagonists more severely - risk their life - count. On this proposal, rather than for averaging, weights representing the relative importance of dimensions in a context serve to determine which predicates are important enough to count as members of the domain of quantification over dimensions. 
Alternatively, this intuition may derive from a similarity-based analysis of multidimensional comparatives. On this alternative proposal, the interpretation of healthier is based on averaging over dimensions; statements of the form " $\mathrm{x}$ is Per than $y$ " are true iff x's weighted sum of degrees in dimensions of $\mathrm{P}$ is higher than $\mathrm{y}$ 's, or iff $\mathrm{x}$ falls under more properties corresponding to dimensions of $\mathrm{P}$ than $\mathrm{y}$ does.

On yet another alternative explanation, the interpretation of derived comparatives is based on information about $\mathrm{x}$ and y's denotation membership. Recall the story about Dan and Sam. Dan's weighted-mean was higher than Sam's by virtue of him being healthier than Sam in two out of three relevant respects. Dan was not healthy at all in the third respect, while Sam was within the normative range in all the three, although barely so. Intuitively, Sam was healthy, but Dan was not, and therefore Sam was healthier than Dan; these judgments suggest that information about the status of entities as healthy or not, provides basis for the interpretation of healthier.

Moreover, these judgments support a conjunctive analysis of healthy, but speak against a conjunctive interpretation of healthier. The latter predicts that in this scenario speakers will reject the use of healthier altogether, because Dan is neither healthier nor less healthy than Sam in every respect, nor are they equally healthy in every respect. The judgments suggest that, when a conjunctive analysis leads to a dead-end, the comparative is still meaningful. Also, an interpretation based on mere number of respects is favored to one based on reported relations between weighted means. The open question, which this paper aims to address, is whether a conjunctive interpretation is available at all for healthier.

\subsubsection{Standard type as an indicator of dimension integration}

Importantly, also the interpretation of one-dimensional adjectives may be mediated by quantification (Yoon 1996; Rotstein and Winter 2005; Kennedy and McNally 2005; Kennedy 2007).

For example, the interpretation of total adjectives - adjectives whose standard of membership is the maximum on their scale - like closed, empty, full and invisible involves no quantification over dimensions; yet these adjectives translate to equivalent formal expressions involving explicit universal quantification over degrees. For instance, invisible holds true of an individual $\mathrm{x}$ iff for every degree $\mathrm{r}, \mathrm{x}$ is invisible to at least degree $r$, which is equivalent to saying that only maximally invisible entities are in fact invisible (Kennedy and McNally 2005).

By contrast, the interpretation of partial adjectives - adjectives whose standard of membership is the minimum on their scale - like open and visible, can be analyzed as involving existential quantification over degrees; e.g., visible holds true of an individual $\mathrm{x}$ iff for some degree $\mathrm{r} \neq 0, \mathrm{x}$ is visible to at least degree $\mathrm{r}$, which is equivalent to saying that even minimally visible entities are visible (Kennedy and McNally 2005).

For Yoon (1996), the scales of these one-dimensional adjectives reflect the relative part of a plural individual that falls under the adjectives; for example, the relative part of an individual that is visible/invisible; the quantity of chairs in a room which are empty; the relative part of one's head that is not covered by hair, etc. Hence, rather than degrees, parts are bound by either universal or existential quantifiers. 
Importantly, the total/partial distinction is different from the conjunctive/disjunctive distinction. The former applies for each dimension separately, whereas the latter is rather about the way judgments of membership in all of the dimensions together determine membership in the adjective. Yet, both distinctions seem to apply uniquely to gradable adjectives, discerning them from, for instance, typical count nouns. In addition, both determine a typological classification of adjectival interpretations by means of a default force of a quantifier. ${ }^{6}$

Quantifiers over parts and degrees determine whether an adjective is total - its standard of membership is the maximum on its scale - or partial - its standard of membership is the minimum on its scale. These quantifiers can be marked explicitly, as in, for instance, completely clean/invisible, and slightly dirty/visible, which contrast with less frequent combinations such as completely dirty/visible and slightly clean/invisible. Syrett (2007) and references therein present corpus data supporting significantly different distributions of partial and total modifiers of adjectives, e.g., slightly and completely, respectively.

We also find naturally occurring examples of exception phrases operating on universal quantifiers over degrees or parts of individuals in total adjectives and negated partial adjectives (COCA 2010). A few of the abundant examples of the former, with the total adjectives empty, bald, and closed, are found in (14); no equivalent examples with the partial antonyms open and hairy are found in the corpus. ${ }^{7}$

(14) a. Entirely bald except for a fringe of grey hair.

b. Malcolm sat in a tiny room, empty except for his chair.

c. The church parking lot is empty except for the cars in the spaces marked "Seniors Only."

d. Kobe's port, which handles more than 12 percent of Japan's exports closed except for emergency use.

e. The ocean salmon fishery is closed except for the Elk River

Likewise, considering invisible and visible, as illustrated in (15), none of the examples of invisible except in COCA to date (20/07/2010) is negated. In sharp contrast, all of the counts of visible except are negated or admit some negative-polarity operator, as in (16).

(15) a. he was below again, invisible except for roiling water and an explosion of bubbles.

b. silent rain, invisible except for brief appearances against dark backgrounds.

c. tall, dressed in black, invisible except for his hands and face.

\footnotetext{
${ }^{6}$ In practice, often, maximum and minimum operations are used instead of quantifiers, but for the argument to go through, this makes little difference. It suffices that the result is equivalent to a representation by means of quantification.

${ }^{7}$ It is possible to say, e.g., The resort is open except for the slopes at the lowest elevation. However, crucially: (i) such an utterance necessarily conveys that all of the slopes are open (except those that are mentioned), not just one of them, and (ii) interestingly, no examples of this sort are actually attested in COCA to date, while abundant equivalent examples with the antonym closed are attested.
} 
d. holding a large picture in place, invisible except for dust and the faint, silvery outline.

e. its blackness made it invisible except for the dimples of its feet.

f. The criado, invisible except for his eyes.

g. The webbing was clear and invisible except where leaves or dirt had become attached.

(16) a. the elevator rides wasn't usually visible except for the bright strobe lights that warned fliers away.

b. Nothing of the spook's face was visible except a bristly bearded mouth that growled, "Welcome to Heaven's Footstool.

c. few things are visible except the Sun, Moon, Jupiter, and Venus.

d. So smeared with blood that the corpse inside isn't visible except for its massive bulk.

e. no nearby motion was visible except our signing.

f. with no skin visible except their eyes.

g. the underside of the roof is no longer visible except for a one- or twoinch strip at the roof peak.

The data in (15) can be driven by tendency of speakers to avoid double negation, as in not invisible, which can be seen as conveying "not not visible"; but this tendency does not explain the prevalence of examples in the negative in (16). All considered, this data supports a classification of invisible and visible as having a default maximum- and minimum-standard, respectively, as these two types of interpretation reduce to universal and existential quantification over parts/degrees, respectively. ${ }^{8}$

Table 1 presents examples of adjectives sorted by their default standard and polarity.

Table 1 Typology of Adjectives by their standard type and polarity

\begin{tabular}{l|l|l}
\hline Standard Polarity & Negative & Positive \\
\hline $\begin{array}{l}\text { Partial (minimum-standard): } \\
\mathrm{P} \Leftrightarrow \mathrm{P} \text { to some degree }\end{array}$ & Sick, Wet, Open, Dirty & $\begin{array}{l}\text { Familiar, Visible, Similar, } \\
\text { Healthier, Sicker, Better, } \\
\text { Worse }\end{array}$ \\
\hline $\begin{array}{l}\text { Total (maximum-standard): } \\
\mathrm{P} \Leftrightarrow \mathrm{P} \text { to every degree }\end{array}$ & $\begin{array}{l}\text { Unfamiliar, Invisible, } \\
\text { Dissimilar }\end{array}$ & $\begin{array}{l}\text { Healthy, Dry, Closed, } \\
\text { Clean, Identical, Full, } \\
\text { Empty }\end{array}$ \\
\hline $\begin{array}{l}\text { Relative (midpoint-standard): } \\
\mathrm{P} \Leftrightarrow \mathrm{P} \text { to a context dependent degree }\end{array}$ & Short, Heavy, Stupid, Ugly & $\begin{array}{l}\text { Tall, Thin, Intelligent, } \\
\text { Beautiful }\end{array}$
\end{tabular}

Returning to dimension integration, a plausible hypothesis is that an adjective's default standard type (maximum vs. minimum) and default dimension-integration (conjunctive vs. disjunctive) are systematically connected. Such a connection is not a

${ }^{8}$ Exception phrases appear to associate more naturally with universal quantifiers over parts, as in (15)(16), than over degrees, as in The door was closed, except for one degree of aperture, and in the naturally occurring example: I was off sick, except I was only half-sick, the rest was tiredness. The latter conveys reduction of degree: rather than being completely sick - sick to any degree the speaker considers relevant in the context of use - the speaker admits being only half-sick, sick to less than the maximum required in the contexts. 
logical necessity, so this hypothesis is not trivial. It is logically possible that, for instance, a conjunctive property holds of an entity iff ALL of the dimensional properties hold of that entity, but not necessarily to the MAXIMAL degree. Nonetheless, the following connection between standard type and dimension integration may exist due to more than a mere coincidence:

(17) Hypothesis set 4: Standard type as a predictive factor

a. $\mathrm{A}$ is conjunctive if and only if $\mathrm{A}$ is total (tends to select a maximum or relative standard across contexts).

b. A is disjunctive if and only if $\mathrm{A}$ is partial (tends to select a minimum or a relative standard across contexts).

c. A is mixed (its classification as conjunctive or disjunctive is completely unbiased and balanced across contexts) iff $\mathrm{A}$ is a predominantly relative adjective.

There are three ways to causally link between standard type and dimension integration. One possibility is that standard type is a more basic property of adjectives than their default dimension integration type, and it affects the choice of dimensionintegration in a systematic way. Consider, for instance, healthy and sick. Let $\mathrm{H}$ be a uniform health scale, and $\mathrm{H}_{1} \ldots \mathrm{H}_{\mathrm{n}}$ be the scales of the health dimensions - the factors that, taken together, help to build $\mathrm{H}$. Assume that to count as healthy, one must be maximally healthy relative to $\mathrm{H}$ (a maximum-standard). Therefore, to count as healthy, one must be maximally healthy in all of the contextually relevant dimensions $\mathrm{H}_{1} \ldots \mathrm{H}_{\mathrm{n}}-$ nobody else can be healthier in any of these respects. Hence, we derived conjunctive integration from an assumption of maximum standard. Now assume that sick is associated with the same scale $\mathrm{H}$, except that the maximum of $\mathrm{H}$ - maximum health functions as the zero point of short. Assume that to count as sick, it suffices to be minimally (somewhat) sick, i.e. to fall minimally short of the maximum of $\mathrm{H}$ (minimumstandard). Therefore, to count as sick, it suffices for one to be sick in but one dimension - to fall minimally short of the maximum of either one of $\mathrm{H}_{1} \ldots \mathrm{H}_{\mathrm{n}}$. Hence, we derived disjunctive integration from an assumption of minimum standard.

In sum, the force of quantification over dimensions may be derived from standard type. According to this hypothesis, in context relative adjectives - adjectives whose standard is undetermined semantically - like, for instance, intelligent, the strategy of dimension integration may also be semantically undetermined (context relative).

An account along these lines derives from a radical-pragmatic view, whereby the analysis of conjunctive and disjunctive adjectives need not be mediated by a quantifying expression. Rather, these adjectives are construed as one-dimensional; their standard type is responsible for the fact that their dimensions, the factors into which their scales can be broken, are seen as universally or existentially bound. On this view, quantifiers are only accommodated when necessary, e.g., in the presence of exception phrases. ${ }^{9}$

An alternative possibility, however, is that the standard type of an adjective is less basic, and is affected by the type of dimension-integration in a systematic way. Assume that to count as healthy, one must be healthy in every respect $\mathrm{H}_{1} \ldots \mathrm{H}_{\mathrm{n}}$ (conjunctive dimension integration). Therefore, minimum health relative to $\mathrm{H}$ cannot possibly suffice

\footnotetext{
${ }^{9}$ I thank François Recanati (p.c.) for this observation.
} 
to count as healthy. The standard of membership of healthy can only be either the maximum on this scale, or some context-relative value that is high enough, so that to reach it one must be at least somewhat healthy in every one of the contextually relevant health dimensions. Thus, if healthy is interpreted conjunctively, it is classified as total or relative. Now assume that being sick in but one dimension suffices for one to count as sick (disjunctive dimension integration). Therefore, being maximally sick relative to $\mathrm{H}$ is not necessary for one to count as sick. A proper standard of membership for sick is any value that is close enough to the maximum of $\mathrm{H}$, so that to reach it, it suffices for one to be sick in but one of the contextually relevant sickness dimensions. So, if sick is interpreted disjunctively, it is classified as partial or relative.

In sum, a standard type may be derived from a default dimension integration type.

A third option is that neither standard type nor dimension integration is more basic. The structure - logical form, or truth conditions - of sentences with conjunctive and disjunctive adjectives may be mediated by quantifying expressions over dimensions and degrees, with certain combinations of quantifiers being more difficult to use than others. For example, combinations whereby the quantifier over degrees and the quantifier over dimensions have the same force - both are universal, or both are existential - may be easier to process than combinations whereby the two quantifiers differ in force, one being universal and one existential. This hypothesis suggests a stronger generalization, namely that any implicit aspects of interpretation of an adjective tend to be mediated by quantification of the same force.

On this view, any implicit parameters of the interpretation of, e.g., invisible degrees, parts, times, locations, etc. - are predicted to be bound by an implicit universal quantifier, whereas any implicit aspects of interpretation of visible are predicted to be bound by an existential quantifier. Interestingly, in support of this hypothesis, among the remaining examples with invisible in COCA (2010), where quantification is over times, places, etcetera, rather than over parts or degrees, none is negated, as shown in (18), whereas all of the equivalent examples with visible are negated, as shown in (19):

(18) a. When the sun is high in the sky, rain-caused rainbows are invisible except when you're at a high vantage point, such as a mountain.

b. ...invisible except from where we'd first spotted him.

c. Their small sizes make most of them invisible except during a total eclipse.

d. ... held in place by a filigree net, invisible except when the sunlight caught it.

e. ... indeed almost invisible except to devotees.

(19) a. The bookshelves are no longer visible except when the sun shines through...

b. ...far too small to be visible except by sophisticated measurements.

c. Green snakes are not visible except in the middle of the day.

d. No men are visible except the scurrying man.

Future research should establish how general this pattern of usage is among adjective.

One advantage of these hypotheses is that they provide a conceptual connection between standard type and dimension integration. Another advantage is that they are economic. Only a standard type, or alternatively only a dimension integration type, must be specified for each adjectival sense. In terms of acquisition, one cue would suffice for the acquisition of both. 
To summarize, we have considered two main types of hypotheses concerning predictive factors for dimension integration defaults of adjectives. By hypothesis 2, antonym polarity is a main predictive factor, while by hypothesis set 4 , standard type is a main predictive factor. An empirical study of dimension integration strategies based on the use of exception phrases may shed light on whether standard type and/or polarity systematically constrain the selection of a dimension-integration strategy in antonym pairs, as well as on whether the interpretation of derived comparatives may be mediated by the default quantification of the adjectives from which they are derived (hypothesis 3). Such a study is presented next, which focuses mainly on 15 positive forms of adjectives, but includes also 3 comparative forms of adjectives and 5 nouns.

\section{A corpus study of dimension-integration strategies}

This section presents a corpus study of dimension integration strategies by examining naturally occurring examples of adjectives modified by exception phrases. This study hinges upon the fact that exception phrases are indicators of universal quantification.

Investigating a balanced linguistic corpus of English is generally preferable to, for instance, Google and the internet. However, the data found in balanced linguistic corpora of English such as the BNC and COCA is very scarce because of the low frequency of negated forms and exception phrases within negated forms. Hence, data was drawn from the internet using the search engine Google. Importantly, the core part of the study did not rely on Google's estimations of number of hits, which are often unreliable. Moreover, the examples for the study were scanned one by one, and repeated entries and entries clearly exhibiting deficient English competence were removed. Thus, two of the main problems pertaining to the use of Google and the internet were surpassed. Relatedly, Lapata and Keller (2005) show in a variety of ways that, despite the many hits by non-native speakers, Google-based frequencies correlate with frequencies obtained from a carefully edited, balanced corpus such as the BNC, and they reliably predict Native-English judgments.

Section 2.1 presents a preparatory study illustrating the usage of exception phrases in a balanced linguistic corpus and their usage in the internet; sections 2.2-2.5 present a systematic Google-based study of hypotheses 1-4, respectively, by means of frequency of exception phrases naturally occurring in the internet.

\subsection{A preparatory study}

\subsubsection{Method}

Material: The preparatory study investigates two samples based on two types of corpora.

Corpora: The first sample was based on the internet and the search engine Google. The hits were scanned one by one, and repeated entries and entries clearly exhibiting deficient English competence were tracked manually and excluded from the sample. Importantly, in order not to beg the research question, no examples were removed due to non-conventional usage of exception phrases with adjectives or otherwise. The second sample was based on the corpus of contemporary American English, henceforth COCA (Davies 2010; http://corpus.byu.edu/coca/). COCA 2010 is the largest balanced 
corpus of American English, with more than 400 million words of text, equally divided among spoken, fiction, popular magazines, newspapers, and academic texts.

Items: The sample based on Google and the internet consisted of naturally occurring uses of except preceded by 8 adjectives of 4 antonym pairs healthy-sick, typical-atypical, identical-different and normal-abnormal. Putting all of the items searched in double quotes, as in: "healthy except", was necessary to reduce much irrelevant data, although it excludes all other word orders. After removal of repeated/non-English entries from the first set of up to 100 Google hits for each adjective, the sample consisted of about 70 remaining examples per adjective. The sample based on COCA 2010 consisted of the naturally occurring uses of except preceded by 10 adjectives, including the 5 antonym pairs healthy-sick, typical-atypical, similar-dissimilar, identical-different and normalabnormal.

adjectives were selected randomly from a set of adjectives which I suspected to be multidimensional, but for the most parts, I had no clear judgment concerning their status as conjunctive, disjunctive, or other. ${ }^{10}$ The adjectives divide to positive vs. negative antonyms, based on morphological considerations, as in normal-abnormal, typicalatypical, and similar-dissimilar, as well as on robust speaker judgments, as in healthysick and identical-different. Judgments concerning the negativity of different are slightly less pronounced; yet, the inclusion of identical and different allows to make crosscomparisons with similar and dissimilar, an option employed in the main study reported in 2.2-2.3.

The procedure consisted of classification of the hits into 4 categories. First, counts were classified as either negative or positive depending on whether the adjective did or did not occur in the scope of negation, as in healthy except vs. not healthy except. Second, the hits were classified as either 'dimension-set readings' or not. Examples of dimension-set readings are ones in which an exception phrase operates on an implicit quantifier over dimensions. The selection of such examples was guided by three general principles.

Principle I consisted of selecting exception phrase indicating quantification over dimensions, rather than over individuals, times, parts or other aspects of interpretation. Only quantification over dimensions provides evidence for multidimensionality and conjunctive, disjunctive, or mixed dimension-integration; hence, examples of the form 'adjective except a dimension, as in Dan is healthy, except for high cholesterol, were classified as 'dimension set uses,' whereas examples in which except does not operate on dimensions, as in (20), were classified as 'non-dimension-set readings.'

(20) Quantification over entities, events, cases, time points, degrees, parts, etcetera:

a. Everyone's been sick (except me--ha!) ...

b. Never been sick (except a cold last year)

c. My hair is healthy except for the front part.

d. Healthy except $\{$ when, by, through the lens of, if $\} \ldots$

Principle II consisted of dismissing exception phrases that operate over dimensions whereby a universal or quasi universal expression explicitly occurs. For example, in

\footnotetext{
${ }^{10}$ The 9 uses of "in every respect except" in COCA 2010 involve mainly adjectives, verbs and preposition phrases of identity and similarity, including identical, of the common sort, like, and fits the ideal.
} 
(21a), we find the expression everything, which suffices to license an exception phrase. Thus, we cannot use this example as evidence for accommodation of an implicit universal. Similar examples of 'non-dimension-set readings' include quantifiers like nothing, as well as adverbs like perfectly, totally, completely, absolutely, otherwise, never, all in all, generally and most:

(21) a. Everything normal except for high bp

b. Nothing/ Little abnormal except for high bp

c. The tests appeared normal except for high bp

d. Totally/ Completely/ Absolutely healthy except for failing eyesight

e. Otherwise/ All in all healthy except for failing eyesight

f. Most vegetarians I know never seem to look very healthy, except for the few that regularly take many vitamin ...

The expression otherwise in (21e) either is universally quantifying on its own right, or triggers the accommodation of a universal, rendering (21e) equivalent to "healthy in every other respect except failing eyesight." The plural the tests in (21c) may also suffice to license an exception phrase. Examples like this have been classified as 'dimension-set readings' only if it was possible to determine based on previous linguistic context that each one of the tests in question included a variety of parameters, such that, e.g., blood pressure was but one of these parameters.

Examples were not dismissed if an explicit quantifier occurred, which was not modified by the exception phrase, as in as in He had always been healthy except for an irregular heartbeat, which is equivalent to "for any time $t$, he was healthy in $t$ in every respect except heartbeat, and hence classifies as a dimension-set reading. In addition, examples were neither dismissed based on modification of the adjective by very, pretty, quite, super, clearly, really, distinctly, so, that, that much, too, apparently, previously and basically, nor if the adjective was preceded by verbs like look, remain, appears, acts or feel, as in (22a), nor if the adjective was used attributively, as in (22b).

(22) a. But like you, I find it annoying being labeled on caloric intake alone - I look healthy and feel healthy (except for being hungry, which is a drag)....

b. In this population of community-dwelling, healthy (except for osteoporosis) postmenopausal women, IGF-I levels were significantly reduced in osteoporotic

Principle III consisted of dismissing as 'non-dimension-set readings' examples in which except merely marked contrast or of mitigation at the clause level, as in (23), or related to a subsequent or preceding clause, not to the adjective preceding it, as in (24).

\section{Contrast /Mitigation: ${ }^{11}$}

\footnotetext{
${ }^{11}$ One could expect the semantics of exception phrases to be similar across uses. Indeed, example such as (23a-c) appear to lend themselves to an analysis involving weakening of a universal statement, albeit not one pertaining to dimensions. Example (23a) can be analyzed as involving quantification over degrees, as it can be naturally interpreted as conveying that the speaker was not 'completely sick' (i.e. sick to a maximal degree); rather the speaker was only 'half sick' (and very tired). On (23b), cases in which sugars
} 
a. I was off sick, except I was only half sick; the rest was tiredness.

b. All sugars are not healthy except in moderation.

c. This would be fine, except if it were not for the fact that ...

(24) A new clause:

a. ...would never know I was sick. Except for being bald, I look great...

b. Nothing interesting ever happens when you're sick, except the occasional...

Example (23c) has a counterfactual interpretation - the situation could be fine, but in actuality, it is not fine - which is not a dimensional reading. On (24b), except relates to nothing interesting rather than to sick.

Based on these principles, a table was compiled for every adjective in the sample, dividing the counts of exception phrases to the categories 'dimension set readings' (' $\mathrm{P}$ except DIM'), 'negated dimension set readings' ('NEG P except DIM'), and 'nondimension-set readings" ('P ELSE'). Table 2 presents by way of illustration the classification of the few naturally occurring uses of healthy except and sick except in COCA. Parts of the tables for the other adjectives are found in appendix 1, excluding those for which no exception phrases exist in COCA up to July 2010.

Table 2: The counts for healthy except and sick except, COCA 2010

The non-dimension set uses under 'P-ELSE' are distinguished from the dimension set uses under 'PEXCEPT-DIM', because the modifier perfectly triggers the introduction of universal quantification in the former, but not latter. In examples of dimension set readings, expressions relating to dimensions are written with capital letters. Elsewhere, quantifying expressions are written with capital letters.

\begin{tabular}{l|l|l|l} 
& P EXCEPT DIM & $\begin{array}{l}\text { P ELSE } \\
\text { (explicit quantification) }\end{array}$ & $\begin{array}{l}\text { NEG P EXCEPT } \\
\text { DIM }\end{array}$ \\
\hline & $\begin{array}{l}\text { The brilliant young judge, } \\
\text { healthy except for his HEART, } \\
\text { had first been }\end{array}$ & $\begin{array}{l}\text { He looks PERFECTLY } \\
\text { healthy except for a CAST on } \\
\text { both his leg and hand. }\end{array}$ & $\begin{array}{l}\text { Jimmy wasn't sick } \\
\text { except at HEART. }\end{array}$ \\
& $\begin{array}{l}\text { Now 91, he is healthy except for } \\
\text { FAILING EYESIGHT }\end{array}$ & $\begin{array}{l}\text { Susie is a ten-month-old baby, } \\
\text { PERFECTLY healthy except } \\
\text { that she has a CONGENITAL } \\
\text { ABNORMALITY OF HER }\end{array}$ & \\
& & $\begin{array}{l}\text { FOOT, commonly known as } \\
\text { clubfoot }\end{array}$ & \\
\hline Healthy & $\mathbf{2}$ & $\mathbf{2}$ & $\mathbf{0}$ \\
\hline Sick & $\mathbf{0}$ & $\mathbf{0}$ & $\mathbf{1}$
\end{tabular}

Conjunctive adjectives are identified by fewer dimension-set uses in negated than non-negated adjectives, as stated in (25a), while disjunctive adjectives are identified by more dimension-set uses in negated than non-negated adjectives, as stated in (24b). Mixed adjectives are identified by balanced scores, as stated in $(25 \mathrm{c}) .{ }^{12}$
a. Conj. Adj.
> $\quad$ Negated Conj. Adj.

come in moderation are excluded from the domain of quantification, which initially should consist of cases in which sugars come in some amount or other. On (23c), the actual index of evaluation is excluded from a domain of quantification consisting of indices, which are introduced by the modal would.

${ }^{12}$ For a detailed explanation, see the discussion of examples (6)-(9) above. 
(Dan is healthy except for BP)

b. Negated Disj. Adj. (Dan is not sick except for BP)

c. Negated Disj. Adj. (Dan is not intelligent except in math)
(Dan is not healthy except for BP)

$\gg$ Disj. Adj.

(Dan is sick except for BP)

Disj. Adj.

(Dan is intelligent except in math)

Based on hypotheses $1 \mathrm{~b}-\mathrm{d}$, and the intuition concerning the multidimensionality of the adjectives selected for this study, I expected to find dimensions set readings for the adjectives in the sample, and my goal was to classify them into these three categories. Based on hypothesis 2, I predicted that antonyms of conjunctive adjectives will be disjunctive, and vice versa.

\subsubsection{Results}

Table 3 presents the data based on Google, which is consistent with the predictions.

In positive adjectives, 184 out of 285 exception phrases operate an implicit quantifiers over dimensions (64\% dimension set uses) and in negative ones 56 out of 285 do $(20 \%)$. All in all a considerable proportion of $42 \%$ (240/570) of the examined exception phrases are dimension set uses. In addition, the adjectives can be classified as conjunctive and disjunctive, in support of hypotheses $1 \mathrm{~b}$-c. Classification respects polar antonymy. Antonyms of conjunctive adjectives are disjunctive and vice versa.

Moreover, most $(75 \%)$ of the dimension-set uses with the negative adjectives sick, atypical, different and abnormal are negated. Conversely, except for one, none of the dimension-set uses of except with the positive adjectives healthy, typical, identical and normal is negated. A Chi-square test of independence suggests that the association between these two groups of adjectives and the two types of dimension-integration (the frequency of exception phrases operating on implicit quantifiers over dimensions of adjectives in negated vs. non-negated contexts) is statistically significant $\left(\chi^{2}=28.32\right.$, df $=9, \mathrm{P}<.001) .{ }^{13}$ The rightmost three columns of Table 3 show that similarly significant results obtain when testing each antonym pair separately. A probability of less than or equal to .05 is a justification for rejecting the null hypothesis that antonym polarity is independent of dimension-integration as measured by frequency of dimension-set readings in negated vs. non-negated contexts. The results remain significant after Bonferroni correction, for all the $\mathrm{p}$-values are smaller than $.05 / 4=.0025$.

Table 3: Exception phrases operating on dimensions of 8 adjectives, GOOGLE 2007

\begin{tabular}{cccc|cccc|ccc} 
Conjunctives: & $\mathbf{P}$ & Neg P Total & Disjunctives: & $\mathbf{P}$ & Neg P Total & $\chi^{2}$ & $\mathrm{p}<-\begin{array}{c}\text { Fisher's } \\
\text { exact test }\end{array}$ \\
\hline Healthy & $\mathbf{4 6}$ & 0 & 70 & Sick & 1 & $\mathbf{7}$ & 70 & 38.815 & .0001 & .0001 \\
Typical & $\mathbf{3 1}$ & 1 & 63 & Atypical & 8 & $\mathbf{1 6}$ & 63 & 23.272 & .0001 & .0001 \\
Normal & $\mathbf{4 6}$ & 0 & 78 & Abnormal & 2 & $\mathbf{2}$ & 78 & 12.707 & .0004 & .005 \\
Identical & $\mathbf{6 0}$ & 0 & 74 & Different & 3 & $\mathbf{1 7}$ & 74 & 59.782 & .0001 & .0001 \\
\hline Total & $\mathbf{1 8 3}$ & 1 & $\mathbf{2 8 5}$ & Total & 14 & $\mathbf{4 2}$ & $\mathbf{2 8 5}$ & $\mathbf{1 6 1 . 8 4 1}$ & $\mathbf{0 . 0 0 0 1}$ & $\mathbf{0 . 0 1}$
\end{tabular}

\footnotetext{
${ }^{13}$ The chi-square test of independence tests whether the frequency of cases possessing some quality varies among levels of a given factor or among combinations of levels of two or more factors.
} 
Table 4 presents the data based on COCA 2010, which is consistent with an analysis of positive adjectives as conjunctive and negative adjectives as disjunctive (driven by the Google data), but unfortunately the data is too scarce rendering it impossible to draw conclusions; for example, there is no data at all about typical, atypical, dissimilar, and abnormal.

Approximately half (57\%) of the uses of except with healthy, similar, identical and normal (45 out of 87) involve implicit quantification over dimensions, and in accordance with a conjunctive analysis, no dimension set use is negated. Nor is any of the cases of explicit quantification over dimensions negated. In addition, in accordance with a disjunctive analysis, the single example of implicit quantification over dimensions with the antonyms sick and different, out of 6 in total, is negated, and so are all of the 4 cases of explicit quantification over dimensions.

Table 4: Exception phrases operating on dimensions of 10 adjectives, COCA 2010

\begin{tabular}{rccc|rccc} 
Conjunctives: & $\mathbf{P}$ & \multicolumn{2}{c|}{ Neg P Total } & Disjunctives: & P & Neg P Total \\
\hline Healthy & $\mathbf{2}$ & 0 & 4 & Sick & 0 & $\mathbf{1}$ & 1 \\
Typical & $\mathbf{0}$ & 0 & 0 & Atypical & 0 & $\mathbf{0}$ & 0 \\
Similar & $\mathbf{6}$ & 0 & 12 & Dissimilar & 0 & $\mathbf{0}$ & 0 \\
Normal & $\mathbf{8}$ & 0 & 19 & Abnormal & 0 & 0 & 0 \\
Identical & $\mathbf{2 9}$ & 0 & 52 & Different & 0 & $\mathbf{0}$ & 5 \\
\hline Total & $\mathbf{4 5}$ & $\mathbf{0}$ & $\mathbf{8 7}$ & Total & $\mathbf{0}$ & $\mathbf{1}$ & $\mathbf{6}$
\end{tabular}

\subsubsection{Discussion}

The findings are consistent with hypotheses 1b-c, according to which some multidimensional adjectives classify as conjunctive and others classify as disjunctive. Moreover, interestingly, over and above the prediction of hypothesis 2 , all the positive antonyms classify as conjunctive, and all the negative ones as disjunctive.

However, the absence of negated dimension-set readings with the positive adjectives may merely reflect the low frequency of negated forms compared to non-negated forms in natural use, casting doubt on the validity of any conclusions. It is well known that negated forms are less frequent than non-negated ones; this fact, rather than a putative conjunctive analysis, may underlay the absence of exception phrases - including ones that operate on dimensions - with negated positive adjectives.

Importantly, without searching separately for negated forms, the Google counts exhibit the same basic pattern as the COCA counts, which is good, but we also encounter the same problem, which is, naturally, not so good. Few counts for each adjective, if any at all, are negated. The low frequency of negated forms may underlie the absence of dimension-set readings with negated positive adjectives, casting doubt on the validity of any conclusions concerning conjunctivity.

Notice, however, that conclusions pertaining to disjunctivity are strengthened considering the low frequency of negated adjectives. More exception phrases operating on dimensions were observed with the disjunctive adjectives in negated than in nonnegated contexts, despite the low frequency of the former in comparison to the latter. 
To establish conjunctivity, more negated forms preceding exception phrases need to be examined. The too few negated forms in COCA lead us to focus on Google. Hence, the study about which the next section reports is designed to improve upon its predecessors in controlling for frequency of negated and non-negated forms of adjectives, by searching separately for negated forms, such as not healthy except. This enables an evaluation of the frequency of dimension-set readings within a set of negated forms (a measure of disjunctivity), vs. their frequency within a set of non-negated forms (a measure of conjunctivity). Another aim of the new study is to extend the number of predicates and search-results investigated, and to include a more variable set of predicates including nouns and relative adjectives, in attempt to reveal preliminary evidence for all of the four different dimension integration strategies predicted by hypothesis set 1 , conjunctive, disjunctive, mixed and similarity-based. Finally, this study addresses hypotheses $2-3$, i.e. how reliable negative antonymy and standard-type are as cues for type of dimension integration.

\subsection{A study of implicit dimension integration in adjectives and their negation}

\subsubsection{Method}

The Material consisted of 1812 naturally occurring examples of exception phrases preceded by each of 23 predicates $\mathrm{P}$, based on Google searches of the internet for the form "P except", as well as, for negated forms such as "not P except", "wasn't P except", and "isn't P except". The need for the latter arises due to the low frequency of negated forms in comparison to non-negated forms in natural usage with most predicates. The searced items were placed in double quotes. The first set of approximately 100 hits in total per predicate were scanned one by one, and repeated entries and entries clearly exhibiting deficient English competence were excluded from the sample. In order not to beg the research question, no examples were removed due to non-conventional usage of exception phrases with adjectives or otherwise.

The noun sample: After removal of repeated/Non-English entries, the sample of exception phrases preceded by nouns consisted of a total of 368 hits, with five nouns, including 100 hits for the noun probes bird except, table except and mother except, as well as 34 hits for each of two additional noun probes capital except and 'carrot except.

Items: The five examined nouns divide to two paradigmatic count nouns - bird and table, and three nouns that are non-paradigmatic in at least one respect each, as follows. The noun carrot has, in addition to the count noun interpretation, also a mass noun interpretation, as in there is (too much) carrot in the salad. On its count interpretation, this noun may be pluralized and an article or a count determiner must precede it, as in $a$ carrot, two carrots, many carrots, etc. On a mass interpretation, it cannot be pluralized or directly counted (\#there is three carrot in the salad), it may occur with a mass determiner (as in too much carrot), and it may stand alone (without an article or determiner). These features render it similar to an adjective, cf. \#three red(s). The noun mother is +human; such nouns often exhibit adjectival features. ${ }^{14}$ In addition, the 9

\footnotetext{
${ }^{14}$ For example, in Hebrew and Catalan such nouns are more likely to combine with degree morphemes than most other nouns, as in the Hebrew hi meod yalda ('she is very girl,' 'she is very girlish'), and $h u$ yoter yeled mimena ('he is more child than her' 'he is more of a child than she is').
} 
tokens of the string "in every respect except" in COCA (2010), involve a thuman noun (wasn't an astronaut at all, in every respect except traveling in space), as well as the adjective human (human in every respect except genetically). The noun capital has an adjectival homonym. In addition, the nouns capital and mother resemble adjectives in being relational and in licensing linguistic arguments; e.g., the noun mother references a relation between a woman and her children (the mother of relation), and the noun capital references a relation between a state and a city (the capital of relation). The availability of an argument structure, like any other adjectival feature, may facilitate the licensing of a dimension argument - and therefore - of universal quantification over dimensions, and of exception phrases that operate on universal quantifiers over dimensions.

The adjective sample: After removal of repeated/Non-English entries, the sample of exception phrases preceded by adjectives consisted of a total of 1444 hits, with any of 18 different adjectives $(\mathrm{n}=18, \mathrm{M}=80, \mathrm{SD}=19.5)$.

Items: The adjectives examined included normal, typical, healthy, familiar, healthier, bad, sick, atypical, abnormal, different, identical, similar, good, better, intelligent, dissimilar, worse, and unfamiliar. Some of these adjectives were selected based on their inclusion in the preparatory study; additional adjectives were selected randomly from a set of adjectives, which I suspected to be multidimensional but had no clear judgment concerning their status as conjunctive, disjunctive, or other.

Of these 18 adjectives, 3 were marked for comparison (worse, better, and healthier), and 15 were unmarked. The 18 adjectives further divide to positive vs. negative antonyms. This division is marked morphologically in 4 pairs (normal-abnormal, typical-atypical, similar-dissimilar, and familiar-unfamiliar), and is based on robust speaker judgments in 3 pairs (good-bad, better-worse, and healthy-sick). Additionally, the pair identical-different was added for the purpose of cross-comparisons with similar and dissimilar, which are near synonyms, except that the standards of identical and dissimilar are more extreme points on the scale than those of similar and different. Considering the 4 combinations identical-different, identical-dissimilar, similardissimilar and similar-different, all in all, the sample allows comparisons between 10 matched pairs of a positive and a negative antonym. Finally, the 18 adjectives divide by standard type; the presentation of methods and results pertaining to this aspect is deferred to section 2.5 .

The procedure consisted of classification of the counts into 4 categories of usage of exception phrases in the following way.

First, the counts were classified as either dimension-set readings or not, according to the principles established in the preparatory study, cf. section 2.1.1. Briefly, exception phrases, which do not operate on dimensions, but rather on a set of entities, events, cases, time points, degrees, parts, etc., were classified as 'non-dimension set readings' (as in, e.g. Everyone's been sick (except me--ha!)), and so were exception phrases accompanied by an explicit (quasi) universal expression like everything, nothing, little, most, mostly, much, totally, completely, absolutely, otherwise, never, and all in all, as in e.g., Nothing abnormal except for high BP. The explicit occurrence of nothing licenses the exception phrase, so this example does not provide evidence for an implicit universal quantifier over dimensions. Exception phrases placed in a different clause than the adjective preceding them were also classified as 'non-dimension set readings', as in ....would never know I was sick. Except for being bald, I look great. Examples of 
'dimension-set readings' included counts preceded by very, pretty, quite, super, clearly, really, distinctly, so, that, that much, too, apparently, previously and basically, as well as adjectives in attributive use or in the scope of verbs like look, remain, appears, acts and feel.

Second, the counts were classified as either negative or positive depending on whether the adjective did or did not occur in a negative context, according to the following principle.

(26) a. A context $\mathrm{C}$ is positive iff counts of the form ' $\mathrm{C} \mathrm{P}$ except DIM' are roughly equivalent to $\lambda \mathrm{x}$. for every $\mathrm{Q}$ except DIM, $\mathrm{x}$ is $\mathrm{Q}$, but $\mathrm{x}$ is not DIM.

b. A context $C$ is negative - downward entailing ${ }^{15}$ - iff counts of the form ' $C P$ except DIM' are roughly equivalent to $\lambda$ x.for every $Q$ except DIM, $x$ is not $\mathbf{Q}$, but $\mathrm{x}$ is DIM.

For example, in Dan is healthy except for high cholestrol, the adjective healthy is not in the scope of negation or a downard entailing expression like hardly. In accordance, it can combine with an exception phrase to convey "not healthy wrt cholestrol but healthy otherwise". Hence, on this example, healthy is placed in a 'positive context'. In contrast, in Dan is not sick except for high cholestrol, the adjective sick occurs under negation and it can combine with an exception phrase in that context to convey "sick wrt cholestrol but not sick otherwise." Hence, on this example, sick is placed in a 'negative context'. This classification criterion is further illustrated in $(27 \mathrm{a}, \mathrm{b})$ :

a. Combinations of the form near normal except Dim count as 'positive contexts', because they are interpreted as "(near) normal in everything and not normal in Dim." In contrast:

b. Combinations of the form hardly normal except Dim count as 'negative contexts', because they are interpreted as "(almost) not normal in everything and normal in Dim."

c. There's nothing I eat that's not healthy, except maybe beer, but to be fair I don't bring that to work with me!

d. My dog does not seem to be showing signs of being sick except for blood in his poop.

Similarly, double negation counts as a 'positive context,' as it conveys the interpretation 'adjective except dim'; for instance, (27c) conveys that everything the speaker eats is healthy, except maybe beer. Conversely, (27d) conveys roughly not sick except for blood in poop and hence counts as a 'negative context'. In sum, forms like nothing normal, never healthy, no different and hardly similar count as 'negative', while almost normal counts as positive. Finally, when negation affects a different clause, rather than the target adjective, as in, Nothing interesting ever happens when you're sick, except..., the example counts as 'positive.

\footnotetext{
${ }^{15} \mathrm{~A}$ downward entailing context $\mathrm{C}$ reverses the direction of entailment (for any $\mathrm{A}$ and B s.t. A entails B but not vice versa, $\mathrm{C}(\mathrm{B})$ entails $\mathrm{C}(\mathrm{A})$, but not vice versa), e.g., red asymmetrically entails colored, but it is not colored that asymmetrically entails not red, the same with hardly colored vs. hardly red, and so on.
} 
In this way, a table was compiled for every adjective in the sample, with counts of the following 4 categories of usage of exception phrases:

(28) a. Dimension set uses in positive contexts (e.g., examples of the form $P$ except Dim)

b. Non-dimension set uses in positive contexts (e.g., P except John/yesterday; all/perfectly $P$ except, etc.)

c. Dimension set uses in negative contexts (examples of the form not $P$ except Dim)

d. Non-dimension set uses in negative contexts (e.g., not $P$ except John/yesterday; not at all P except, etc.)

By way of illustration, representative examples from the tables for healthy and sick are found in appendix 2. The tables served to calculate two important indices for each adjective, a conjunctivity index - $|(28 \mathrm{a})| /|(28 \mathrm{a}+\mathrm{b})|$ (the frequency of dimension-set uses in positive contexts) and a disjunctivity index $-|(28 \mathrm{c})| /|(28 \mathrm{c}+\mathrm{d})|$ (the frequency of dimension-set uses in negative contexts).

\subsubsection{Predictions}

The predictions based on hypothesis-set 1 are as follows. For conjunctive adjectives like healthy we predict that the frequency of dimension set uses will be significantly larger in positive than in negative contexts, as stated in (29a). For disjunctive adjectives, we predict the opposite, as stated in (29b). Based on the disjunctive results in the study reported in 2.1, we expect 'significantly larger' to be 3 times as large or larger. For nouns we predict no dimension set readings to occur as stated in (29d), while for mixed adjectives, like, possibly, the relative adjective intelligent, we expect dimension set readings to be licensed and be equally frequent in negative and positive contexts, as stated in $(29 \mathrm{c}){ }^{16}$

(29) Hypothesis set 1:

Predicate typology based on strategies of dimension integration

a. Conjunctive adjectives: |(28a)|/|(28a+b)|) >>|(28c)|/|(28c+d)|.

b. Disjunctive adjectives: $|(28 \mathrm{a})| /|(28 \mathrm{a}+\mathrm{b})|)<<|(28 \mathrm{c})| /|(28 \mathrm{c}+\mathrm{d})|$.

c. Mixed adjectives: $\quad|(28 \mathrm{a})| /|(28 \mathrm{a}+\mathrm{b})|) \cong|(28 \mathrm{c})| /|(28 \mathrm{c}+\mathrm{d})| \gg>0$.

d. Nouns: $\quad|(28 \mathrm{a})| \cong|(28 \mathrm{c})| \cong 0$.

Hypothesis sets 2-4, pertaining to predictive factors of type of dimension integration, are as follows (notice the new data driven hypothesis in $2 b$ ):

(30) Hypothesis set 2: Antonymy as a predictive factor

a. Antonyms differ with respect to the default force of the quantifier binding their dimensions: $\mathrm{P}$ is conjunctive iff $\mathrm{P}$ 's antonym is disjunctive.

\footnotetext{
${ }^{16}$ Dimensions of yet other adjectives might in principle be bound by quantifiers such as many (beautiful and tasty, perhaps?), thereby exception phrases would be bad in both positive and negative contexts, but, precisely for this reason, I would not know how to test this hypothesis.
} 
b. Positive antonyms are conjunctive, negative ones are disjunctive.

Hypothesis 3: Compositionality

Derived comparatives are classified according to the default dimension integration strategy of the adjective they derive from.

Hypothesis set 4: Standard type as a predictive factor

a. A is conjunctive if and only if $\mathrm{A}$ is total (selects mainly a maximum/relative standard across contexts).

b. A is disjunctive if and only if A is partial (selects mainly a minimum/relative standard across contexts).

c. A is mixed (A has both conjunctive and disjunctive interpretations, which are equally frequent) iff $\mathrm{A}$ is a predominantly relative adjective.

The results are presented and discussed in the following order. Section 2.3 focuses on hypothesis set 1 , section 2.4 focuses on hypothesis sets 2 and 3 , and section 2.5 focuses on hypothesis set 4.

\subsection{Hypothesis set 1: A typology based on strategies of dimension integration}

Sections 2.3.1-2.3.2 address adjectives and sections 2.3.3-2.3.4 compare them to nouns.

\subsubsection{Results - Hypothesis 1a-c}

The predictions generally are borne out. 550 dimension-set uses are found with the examined adjectives in total, which is $36.5 \%$ of the 1444 exception phrases, which were preceded by an adjective. In addition, dimension set uses are found with all the examined adjectives, as shown in figure $1(\mathrm{M}=30.5, \mathrm{SD}=20$, Median 23.5).

Figure 1: $36.5 \%$ of the 'Adj. except' hits are of the type 'Adj. except a dimension':

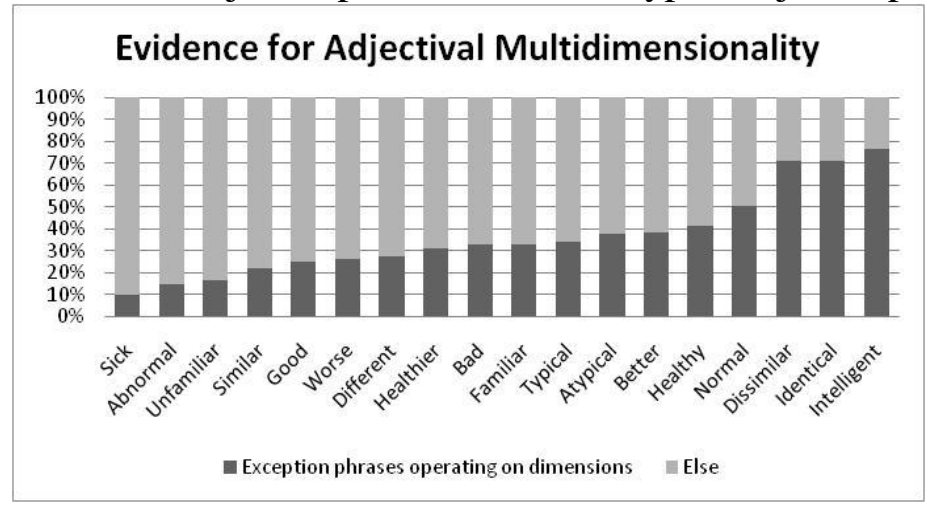

The adjectival sample included a total of 883 positive hits $(M=49, S D=17.7)$ and additional 561 negative hits $(\mathrm{M}=31$; $\mathrm{SD}=13.96)$. The total number of conjunctive uses - namely, dimension set uses in positive contexts - for all adjectives was 357 out of 883 examples of positive contexts $(40 \%)$. The total number of disjunctive uses - namely, dimension set uses in negative contexts - for all adjectives was 193 out of 561 examples in negative contexts $(34 \%)$. 
Furthermore, the frequency of dimension-set uses with the 5 adjectives in (34a) is 37 times higher in positive than in negative contexts. Thus, the prediction of hypothesis $1 \mathrm{~b}$, stated in (29a), is borne out. Some adjectives exhibit greater conjunctivity than disjunctivity values: $|(28 \mathrm{a})| /|(28 \mathrm{a}+\mathrm{b})|) \gg|(28 \mathrm{c})| /|(28 \mathrm{c}+\mathrm{d})|)$, supporting a default conjunctive classification. ${ }^{17}$ Conversely, the frequency with the 5 adjectives in $(34 \mathrm{~b})$ is 3-10 times higher in negative than in positive contexts. Thus, the prediction of hypothesis 1c, stated in (29b), is borne out. Some adjectives exhibit smaller conjunctivity than disjunctivity values: $|(28 \mathrm{a})| /|(28 \mathrm{a}+\mathrm{b})|) \quad<\quad|(28 \mathrm{c})| /|(28 \mathrm{c}+\mathrm{d})|)$, supporting a default disjunctive classification.

(34) a. normal, typical, healthy, familiar, healthier

b. bad, sick, atypical, abnormal, different

c. identical, similar, good, better, intelligent, dissimilar, worse, unfamiliar

Finally, (34c) lists a third set of 8 adjectives, which exhibit a mixed pattern, starting from the borderline conjunctives and ending with the borderline disjunctives. The prediction of hypothesis 1d, stated in (29c), is borne out. Some adjectives exhibit relatively high, but balanced conjuctivity and disjunctivity values: $|(28 \mathrm{a})| /(28 \mathrm{a}+\mathrm{b}) \mid) \cong$ $|(28 c)| /|(28 c+d)|>>0)$.

\subsubsection{Discussion}

The fact that more than a third (36.5\%) of the exception phrases preceded by an adjective operate on an implicit quantifier over dimensions supports the hypothesis that dimension integration via quantifiers is available for adjectival dimensions.

Moreover, the findings support a typology of adjectives based on their default dimension integration, whereby some adjectives default conjunctive integration, others default disjunctive integration, and some are mixed - unbiased. Importantly, the latter regularly license exception phrases with dimension-set readings. Hence, their dimensions often are integrated via logical operations, in support of the hypothesized view of multidimensional adjectives. However, no operation is set semantically to be their default. Pragmatic factors appear to determine whether, for example, being intelligent in but ONE dimension (say, mathematics) suffices to count as intelligent or ALL contextually relevant intelligence measures count in each context.

These results indicate dimension integration defaults in adjectives modified by exception phrases. The question is whether they reflect a tendency of adjectives toward logical dimension integration independently of the presence of an exception phrase. The exception phrases preceded by nouns may provide a preliminary answer to this question. The psychological research of linguistic concepts extensively supports an analysis of nouns as similarity-based (Murphy 2002, ch. 3). If this view is correct, we expect exception phrases not to operate on the dimensions of nouns, as those are not bound by

\footnotetext{
${ }^{17}$ The data are presented in detail in Table 5, which is found in section 2.4, which discusses the role of antonym polarity in relation to dimension integration.
} 
quantifiers. A significantly lower frequency of dimension set readings in nouns than in adjectives will reflect a tendency of adjectives toward logical dimension integration independently of the presence of exception phrases, for otherwise, a difference between adjectives and nouns will remain unexplained. To a preliminary investigation of this hypothesis we now turn.

\subsubsection{Results - Hypothesis 1d}

The predictions are borne out. None of the 368 exception phrases examined with the nouns bird, table, mother, carrot, and capital operates on dimensions. Thus, the prediction of hypothesis 1a, stated in (29d) is borne out - null conjunctivity and disjunctivity values: $|(28 \mathrm{a})| \cong|(28 \mathrm{c})| \cong 0$ - supporting a non-quantificational, similaritybased dimension-integration hypothesis for nouns.

\subsubsection{Discussion}

Only five nouns were studied here, but this is mainly because the cognitive psychological branch of research of linguistic concepts provides us with an extensively supported view of nouns as similarity based; thus, the present study focused mainly on adjectives with multiple respects, about which we know very little as yet.

The five examined nouns included two paradigmatic count nouns - bird and table. The fact that no exception phrases were observed which operate on an implicit quantifier over their dimensions is consistent with a similarity-based categorization view, cf. Murphy (2002: ch. 3), and references therein. According to this view the dimensions of such nouns are combined via averaging, as discussed in section 1, not through logical operations such as those denoted by 'all' or 'some'.

Furthermore, three more nouns were examined, each of which is non paradigmatic of the category noun in at least one respect: the noun carrot has a prominent mass noun interpretation, the noun mother is +human, the noun capital has an adjectival homonym, and the nouns capital and mother resemble adjectives in being relational and in licensing linguistic arguments. Given these similarities to adjectives, one could expect these nouns to resemble adjectives also with respect to the licensing of a dimension argument, and in accordance, one could expect to observe exception phrases operating on their dimensions. The fact that no dimension set readings were observed supports the view that, by virtue of being nouns, categorization under them is based on similarity (averaging), not quantification. Quite the opposite holds of multidimensional adjectives, which appear to default different dimension integration strategies.

This is a preliminary investigation. More nouns and more exception phrases per noun must be studied in the future to support or refute this suggestion properly. However, the inclusion of nouns was important to establish that the reported results reflect a tendency of adjectives toward logical dimension integration independently of modification by an exception phrase. If it were the case that adjectives and nouns tend equally much toward similarity-based integration, such that logical dimension integration occurs only in the context of exception phrases, no difference between the adjectives and the nouns in the sample would have been observed. Modification by an exception phrase triggered implicit quantification over dimensions in the adjectives, but 
not in the nouns, for the former, generally, tend more toward logical dimension integration than the latter.

The distinction between different dimension-integration strategies appears to have neural and developmental correlates; for a review of research of invented categories with logical, 'rule-based' vs. non-logical, similarity-based categorization criteria see Ashby and Maddox (2005). The perspective of different default types of dimension integration sheds new light on a variety of semantic contrasts between adjectives and nouns, which go beyond the scope of this paper, but are discussed in Sassoon (2007; 2011b).

We can now turn to the task of identifying semantic-pragmatic factors, which determine whether an adjective is by default conjunctive, disjunctive, or mixed. If this typology of adjectives is real, as the findings suggest, predictive factors must exist, for otherwise how can it be that children acquire this typology? Predictive factors are also needed for adults to use when 'guessing' whether a particular utterance of an adjective is to be read conjunctively or disjunctively.

\subsection{Hypothesis 2: Antonym polarity as a predictive factor}

\subsubsection{Results}

The results suggest that antonym polarity (positive/negative) is a reliable predictor of integration type, supporting hypothesis $2 \mathrm{a}$,b. The clearly conjunctive adjectives in (34a) - normal, typical, healthy, familiar, healthier - are all positive, while the clearly disjunctive adjectives in (34b) - bad, sick, atypical, abnormal, different - are all negative. On top of this, we see on (34c) that the borderline conjunctive adjectives identical, similar, good, better, intelligent - are positive, while the borderline disjunctive - dissimilar, worse, unfamiliar - are negative. Thus, a sharp boundary between conjunctive and disjunctive adjectives can be drawn by classifying all of the positive adjectives as 'conjunctive' and all of the negative antonyms as 'disjunctive', as figure 2 illustrates.

A Chi-square test of independence for the 10 pairs of positive and negative antonyms in positive and negative contexts listed in Table 5 below yields that the association between antonym polarity (negative/positive) and disjunctive vs. conjunctive integration (frequency of dimension set uses with adjectives in negative vs. positive contexts) is statistically significant $(\chi 2=38.64, \mathrm{df}=12, \mathrm{p}<.00013)$. The same results are obtained when testing each antonym pair separately, except for the pair of comparative forms better vs. worse, as the rightmost columns of Table 5 show. ${ }^{18}$ A chisquare probability of less than or equal to .05 is a justification for rejecting the null hypothesis that antonym-type is independent of dimension-integration type. Except in the case of similar-dissimilar, the results remain significant also after Bonferroni correction, as all the p-values are smaller than $.05 / 10=.005$.

\footnotetext{
${ }^{18}$ The statistical results at the last three lines of the table are not relevant for the antonymy hypothesis.
} 


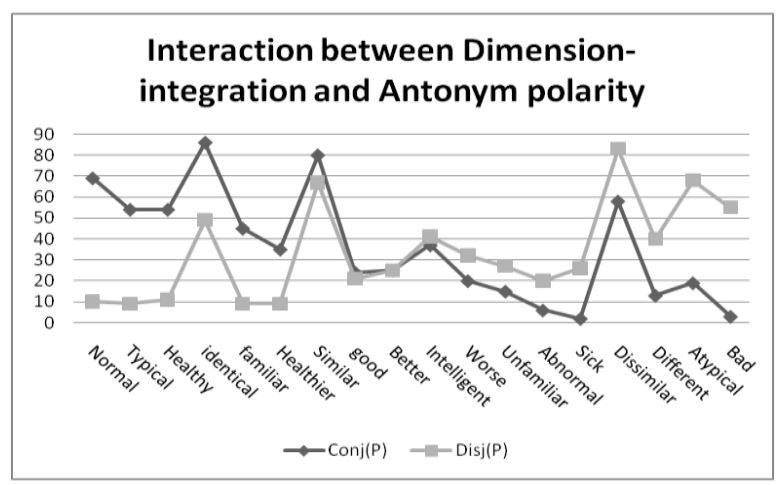

Figure 2: Disjunctivity vs. conjunctivity values in positive vs. negative antonyms An adjective's disjunctivity and conjunctivity scores are the frequencies of dimension sets uses with this adjective in negative and positive contexts, respectively.

Table 5: The frequency of dimension-set uses of except

For any P, P's conjunctivity value equals the frequency of dimension set uses in positive contexts: $\operatorname{conj}(\mathrm{P})$ $=\mid \mathrm{P}$ Except Dim $\mid / \mathrm{P}$ except $\mid$, and $\mathrm{P}$ 's disjunctivity value equals the frequency of dimension set uses in negative contexts: $\operatorname{Disj}(\mathrm{P})=\mid \operatorname{Neg} \mathrm{P}$ Except $\operatorname{Dim}|/|$ Neg P except $\mid$. Notice that this table matches between different and similar, as well as between different and identical; likewise for dissimilar. Also, the statistical results at the left columns of the last three lines of the table represent comparisons between each one of the derived comparative and the adjective it derives from.

\begin{tabular}{c|ccc|ccc|ccc}
$\%$ & POS P & Conj(P) & Disj(P) & NEG P & Conj(P) & Disj(P) & $\boldsymbol{\chi}^{\mathbf{2}}$ & $\mathbf{p}<$ & $\begin{array}{c}\text { Fisher's } \\
\text { exact test: }\end{array}$ \\
\hline Adj & Healthy & $\mathbf{5 4}$ & 11 & Sick & 2 & $\mathbf{2 6}$ & 47.10 & .0001 & .0001 \\
& Normal & $\mathbf{6 9}$ & 10 & Abnormal & 6 & $\mathbf{2 0}$ & 39.59 & .0001 & .0001 \\
& Typical & $\mathbf{5 4}$ & 9 & Atypical & 19 & $\mathbf{6 8}$ & 59.68 & .0001 & .0001 \\
& Similar & $\mathbf{8 0}$ & 67 & Dissimilar & 58 & $\mathbf{8 3}$ & 5.09 & .024 & .0256 \\
& Identical & $\mathbf{8 6}$ & 49 & Dissimilar & 58 & $\mathbf{8 3}$ & 14.08 & .0002 & .0002 \\
& Similar & $\mathbf{8 0}$ & 67 & Different & 13 & $\mathbf{4 0}$ & 13.99 & .0002 & .0002 \\
& Identical & $\mathbf{8 6}$ & 49 & Different & 13 & $\mathbf{4 0}$ & 21.89 & .0001 & .0001 \\
& Good & $\mathbf{2 4}$ & 21 & Bad & 3 & $\mathbf{5 5}$ & 30.39 & .0001 & .0001 \\
& Familiar & $\mathbf{4 5}$ & 9 & Unfamiliar & 15 & $\mathbf{2 7}$ & 22.86 & .0001 & .0001 \\
& Intelligent & $\mathbf{3 7}$ & 41 & --- & & & & & \\
\hline Comp. & Better & $\mathbf{2 5}$ & 25 & Worse & 20 & $\mathbf{3 2}$ & 1.38 & .2407 & .3188 \\
& Healthier & $\mathbf{3 5}$ & 9 & --- & & & .22 & .6402 & .8014 \\
& Better & $\mathbf{2 5}$ & 25 & --- & & & .11 & .7455 & .8379 \\
& --- & & & Worse & 20 & $\mathbf{3 2}$ & 18.37 & .0001 & .0001 \\
\hline & $\mathbf{M}$ & $\mathbf{5 6 . 3}$ & $\mathbf{3 0 . 6}$ & M & $\mathbf{2 0 . 7}$ & $\mathbf{4 7 . 4}$ & & &
\end{tabular}

The clustering of positive antonymy with conjunctivity and negative antonymy with disjunctivity is a post-hoc discovery. It is therefore useful to test whether this clustering predictably generalizes to other multidimensional adjectives. A $2 \times 2$ two-factor mixed ANOVA with positive vs. negative antonym polarity as a between-subject variable, and frequency of dimension-set uses in positive vs. negative contexts as a repeated measure, yields a significant interaction between antonym polarity and dimension set usage in positive vs. negative contexts, i.e. frequency of conjunctive and disjunctive dimension integration $(\mathrm{F}=51.92, \mathrm{P}<.0001)$. This interaction is apparent from the fact that, as Figure 2 shows, the conjunctivity values of positive adjectives in the sample are higher 
than their disjunctivity values $(\mathrm{M}=.51 \mathrm{SD}=.22$ vs. $\mathrm{M}=.25, \mathrm{SD}=.21)$, whereas those of negative adjectives are all smaller than their disjunctivity values $(\mathrm{M}=.17, \mathrm{SD}=.18$, vs. $\mathrm{M}=.44 ; \mathrm{SD}=.23$ ). In addition, the conjunctivity values are higher in positive than in negative adjectives $(\mathrm{M}=.51, \mathrm{SD}=.22$ vs. $\mathrm{M}=.17, \mathrm{SD}=.18$, resp. $)$, whereas the disjunctivity values are generally lower in positive than in negative adjectives $(M=.25$, $\mathrm{SD}=.21$ vs. $\mathrm{M}=.44, \mathrm{SD}=.23$.)

In addition, an analysis of variance with respect to frequency of dimension set readings has been conducted for the following four correlated samples:

Positive adjectives in positive contexts (i.e., conjunctivity in positive antonyms), as in healthy except or very similar except $(\mathrm{M}=.51, \mathrm{SD}=.22)$;

Positive adjectives in negative contexts (i.e., disjunctivity in positive antonyms), as in not healthy except or hardly similar except $(\mathrm{M}=.25, \mathrm{SD}=.21)$;

(iii) Negative adjectives in positive contexts (i.e. conjunctivity in negative antonyms), as in very sick except $(\mathrm{M}=.17, \mathrm{SD}=.18)$;

(iv) Negative adjectives in negative contexts (disjunctivity in negative antonyms), as in not sick except or hardly sick except $(\mathrm{M}=.44, \mathrm{SD}=.23)$.

A non-parametric Friedman test for the 10 matched pairs in Table 5, yields significant results, meaning that the four samples generally are different (mean ranks 3.6, 2, 1.3, 3.2 resp.; $\left.\chi^{2}=20.1, \mathrm{P}=.0002\right) .{ }^{19}$ Differences are expected neither between samples (i) and (iv), nor between (ii) and (iii), which are in fact reasonably similar (their means are .49 vs. .44 , and .22 vs. .17, respectively), meaning that only the four differences of interest contribute to the significance value. Non-parametric Wilcoxon signed-ranks test for the significance of the difference between the distributions of two samples of 10 matched pairs yields significant result for three of these differences:

(i) positive adjectives in positive vs. negative contexts (mean ranks: 13.8 and 7.3, respectively; $\mathrm{W}=55, \mathrm{z}=2.78, \mathrm{P}=.0054$ );

(ii) negative adjectives in positive vs. negative contexts (mean ranks: 7 and 14.1, respectively; $\mathrm{W}=-55, \mathrm{z}=-2.78, \mathrm{P}=.0054)$, and

(iii) positive vs. negative adjectives in positive contexts (mean ranks: 14.5 and 6.5, respectively; $\mathrm{W}=55, \mathrm{z}=2.78, \mathrm{P}=.0054)$.

The difference between positive and negative adjectives in negative contexts only approaches significance (mean ranks: 8.3 and 12.7, respectively; $\mathrm{W}=-37, \mathrm{z}=-1.86,2-$ tailed $\mathrm{P}=.0629$, 1-tailed $\mathrm{P}=.0314$ ); the outlier is different, which is less disjunctive than both similar and identical. The differences between (i) and (iv), and between (ii) and (iii) are non-significant as expected.

Finally, frequency of dimension set uses is lower in negative than in positive contexts $(\mathrm{M}=35.83, \mathrm{SD}=26$. vs. $\mathrm{M}=33.44, \mathrm{SD}=22.92)$, but this difference is not significant (t-test for $\mathrm{n}=18$, yields $\mathrm{t}=.3089, \mathrm{P}=.7612$ ). Likewise, frequency of dimension set uses is slightly lower in negative than in positive antonyms $(\mathrm{M}=38, \mathrm{SD}=$ 24.53. vs. $\mathrm{M}=30.44, \mathrm{SD}=24.1)$, but this difference is not significant $(\mathrm{t}=.93, \mathrm{P}=.361)$.

\footnotetext{
19 A non-parametric analysis of variance does not assume normal distributions; similarly significant results are obtained with parametric tests (ANOVA), as well as with an analysis for independent samples for all of the 18 adjectives, including intelligent and healthier $(\mathrm{F}=5.15, \mathrm{P}=.005)$. Finally, a matching of different with similar, and dissimilar with identical yields significantly better results than a matching of similar with dissimilar and identical with different. This finding aligns with Google's frequency estimation, which for similar with different is in the order of hundreds of millions (486 and 639, resp.), while for identical with dissimilar it is 'only' in the order of tens of millions (55 and 27 resp.)
} 
As for hypothesis 3, the statistical results at the last three lines of table 5 represent comparisons between each one of the derived comparatives and the adjective it derives from; the non significance of the differences between healthy and healthier and between good and better are in line with hypothesis 3, whereby comparatives inherit the default integration type of the adjective they derive from. The difference between bad and worse is significant; still, in line with the hypothesis, both bad and worse are disjunctive, except that bad is more extremely so than worse.

\subsubsection{Discussion}

These results are suggestive of the following generalizations. In positive adjectives conjunctivity is predictably higher than disjunctivity, whereas in negative adjectives it is predictably lower; Also, conjunctivity is predictably higher in positive than in negative antonyms, whereas we can say that disjunctivity is predictably lower with an almost, but not quite high enough level of confidence $(\mathrm{P}<.063)$. This last fact may be driven by tendency of speakers to avoid double negation, as in, e.g., not abnormal which, given a logical-negation theory of antonymy, is seen as conveying "not not normal".

The present findings pertaining to antonym polarity as a predictive factor are surprisingly clear-cut. These findings support an analysis of negative antonyms as negations of their positive counterparts (cf. Heim 2006, 2008; Büring, 2008), for otherwise why would the force of quantifier over dimensions systematically vary in antonym pairs? These findings are preliminary, but suggestive of the importance of future inquiry into possible interactions between antonymy and quantifier force in multidimensional adjectives. The quantifier force appears to be affected by compositional processes. While positive adjectives are associated with a default quantifier, negative ones inherit it, so to speak, and the force of the quantifier is switched due to a negation operator in their logical form, in which scope the quantifier falls:
a. $\lambda x \cdot \operatorname{sick}(\mathrm{x}) \Leftrightarrow \lambda \mathrm{x} \cdot \neg$ healthy(x)
$\Leftrightarrow$
b. $\lambda \mathrm{x} . \neg \forall \mathrm{Q} \in \mathrm{DIM}$ (healthy): healthy-wrt(x,Q)
$\Leftrightarrow$
c. $\lambda x . \exists \mathrm{Q} \in \mathrm{DIM}($ healthy): $\rightarrow$ healthy-wrt( $\mathrm{x}, \mathrm{Q})$
$\Leftrightarrow$
d. $\lambda x \cdot \exists Q \in D I M($ healthy): $\quad$ sick-wrt $(x, Q)$

Notice, however, that for this to work, negation in (35b-c) should stand for normal sentential negation, not for the slightly different operator - 'adjectival negation' - used by Heim $(2006,2008)$ and Büring (2008). This difference is problematic if adjectival negation is crucial for an account of denotation gaps for adjectives like sick and healthy, namely, the fact that entities may fall under not-healthy without falling under sick; entities may be neither healthy with respect to blood pressure, nor sick with respect blood pressure, etc. (Rotstein and Winter 2005). However, Solt (2010) shows in a series of experiments that sentential negation can also create denotation gaps; for example, entities may be judged neither tall nor not tall. The use of antonyms like short differs from the use of syntactic negation - not tall - only insofar as it triggers interpretations with larger gaps. The difference between not healthy and sick may therefore be quantitative, rather than qualitative; perhaps it is merely pragmatics that explains it. 
Interestingly, both the COCA data (cf. 2.1) and the Google data suggest that variance in interpretation correlates with quantifier type. For example, the data supports a default conjunctive analysis of healthy and typical and a default disjunctive analysis of sick and atypical. My impression is that the apparent counterexamples to these analyses systematically belong to secondary interpretations of these adjectives. For example, in (36a) healthy merely conveys 'good'; with such a sense it can be used disjunctively. Similarly, (36b) is an 'exceptional' conjunctive use of atypical. However, in scientific contexts atypical is used to convey a non-default interpretation "belongs to an atypical group", which is, apparently, conjunctive. For a potential subject to belong to an atypical group in a scientific research (say, specific language impairment; aphasia, etc.), that individual should ideally exhibit many if not all of the symptoms defining that group.

a. ... working like a dog this weekend as I do every weekend. 24 hours in 2 days. Not healthy, except for my bank account.

b. Patient 4 was atypical except for the high-pitched voice.

Similarly, as the tables in Appendix 2 illustrate, exceptional uses of healthy as disjunctive and of sick as conjunctive are more abstract, metaphoric, or otherwise different from their default uses. For instance, the exceptional example of a dimension set reading of sick in a positive context exemplifies a novel usage, whereby sick conveys cool (Jessica Olsen, p.c.). I leave it for future research to determine how far variance in interpretation can help in predicting dimension integration, in particular in the usage of mixed adjectives like intelligent and good.

The classification of the antonyms in the sample into positive and negative is for the most part, relatively straightforward and uncontroversial. However, this is not the case for many other adjectives not morphologically marked for antonymy. Future research should determine precisely which notion of negative antonymy is indicative of dimension-integration type; for a review of a rich battery of tests for negative antonymy resulting in only partially overlapping sets see Lehrer (1985); for a psycholinguistic characterization see Giora (2006).

The results of this study contribute to the research into this problem in highlighting a new potential generalization. The present study suggests that judgments of 'negativity' relate to slightly different phenomena in one dimensional vs. multidimensional adjectives. In one-dimensional adjectives, like tall vs. short, positivity relates to the existence of a property, e.g., much height, whereas negativity relates to the lack of much of that property. However, in multidimensional adjectives like healthy and sick, positivity seems to relate to a generalization - membership under EVERY dimensional property, whereas negativity seems to relate to the existence of a counterexample to that generalization - failure to reach the membership norm of some dimension.

Finally, according to hypothesis 3 , dimensions of comparative adjectives may be integrated via the default operation of the adjectives from which they derive. Thus, the conjunctivity and disjunctivity values of derived comparatives are predicted to resemble those of the adjectives from which they derive. While the sample of adjectives studied includes but three comparative adjectives (healthier, better, and worse), interestingly this prediction appears to be borne out for all the three cases; i.e. healthy is conjunctive, and indeed so is healthier. It tends to be interpreted as conveying "healthier in every 
respect"; good and better are both mixed, and bad and worse are both disjunctive (tend to be interpreted as conveying 'Adj. in some respect'), albeit the former is a clear case and the latter borderline one. Future research of this question may lead to fruitful results.

To conclude, considering antonym polarity, we supported an account whereby compositional processes affect the force of implicit quantifiers over dimensions. Such an account receives a preliminary support also from the fact that the dimensions of the three derived comparatives in our sample integrate via the default operation of the adjectives from which they derive. Many questions for the future arise, pertaining to the study of gradability and comparison. Two important issues are the following. First, what are the implications of the quantifier over dimensions in the interpretation of adjectives for the analysis of comparison statements? Second, the present study suggests that the degree functions of multidimensional adjectives are not (or not always) based on averaging; if so, then how are they construed? One option worth considering is that they are derived from the denotation along the lines proposed in vagueness based gradability theories (Kamp 1975; Klein 1980; van Rooij 2010).

We will now turn to the last part of our study - a test of hypothesis-set 4 . To what extent does the distinction between adjectives with a maximum or relative standard (total adjectives) vs. ones with a minimum or relative standard (partial adjectives), correlate with the conjunctive - disjunctive classification? Our sample allows us to make a preliminary examination of this question.

\subsection{Hypothesis set 4: Standard type as a predictive factor}

\subsubsection{Method}

The 18 adjectives in the sample were divided by standard type to partial adjectives adjectives that tend to have a minimum or a context relative standard - and total adjectives - ones that tend to have a maximum or a context relative standard. Two different classification methods were used.

First, adjectival standard types were classified based on established tests of inference patterns sensitive to standard type (Kennedy and McNally 2005; Rotstein and Winter 2005; Kennedy 2007). This classification was based on data from the above cited literature, and was confirmed by judgments of at least two informants per adjective. ${ }^{20}$

\footnotetext{
${ }^{20}$ The tests used to determine standard type (Winter and Rothstein 2005; Kennedy and McNally 2005): First, in partial (minimum standard) adjectives, unlike relative adjectives, any non-zero degree in P entails P-hood. Thus, the interpretation of (ia), but not of (ib), intuitively is judged to be contradiction.

(i)a. \#The door is not open, but it is still ajar [contradiction]

b. Sam is not tall but his height is normal for his age [No contradiction]

Second, the negation of a total adjective entails the assertion of its (partial) antonym, but in relative adjectives entities may fall under neither P nor P's antonym, as illustrated in (iia) vs. (iib), respectively.

(ii)a. The door is not closed $\Rightarrow \quad$ The door is open.

b. Sam is not short $\quad \Rightarrow \quad$ Sam is tall.

Third, mid-point modifiers like half or partially entail P-hood in partial adjectives and non-P-hood in total adjectives (iiia-b). They entail membership under neither $\mathrm{P}$ nor not-P in relative adjectives (iiic).

(iii)a. The door is half open $\Rightarrow \quad$ The door is open.

b. The door is half closed $\Rightarrow \quad$ The door is not closed.

c. The tree is half tall $\Rightarrow \quad$ The tree is (not) tall.
} 
Second, a tighter connection between standard type and dimension integration may be revealed by replacing this binary distinction (total/partial), with a scalar quantitative estimation of the frequency of use of an adjective as total, partial or relative. In particular, frequency of co-occurrences of adjectives with certain degree-modifiers can indicate a default relative, total, or partial standard type (Rotstein and Winter 2005; Kennedy and McNally 2005). Experimental research of acquisition supports the view of degree modifiers as cues for acquiring standard type (Syrett 2007; Tribushinina 2010a). Moreover, Google's estimations of the frequency of modifiers as a measure of standard type is precisely the right thing to compare to the Google-based conjunctive vs. disjunctive measurements.

Hence, Google searches of the internet were conducted for each adjective preceded by modifiers characteristic of total adjectives (entirely and perfectly), partial adjectives (slightly and partially), and relative adjectives (very), respectively. All items were put in double quotes and were searched in the same day, using the same computer.

\subsubsection{Results}

The characterization of standard type based on standard tests of judgments (Rotstein and Winter 2005; Kennedy and McNally 2005) results in a classification that cross-cuts the classification by antonym polarity. Hence, statistically significant differences along the parameters of interest are unlikely to occur. Indeed, illustrating briefly, the 10 total/relative adjectives unfamiliar, normal, typical, healthy, identical, good, dissimilar have higher normalized conjunctivity values than the 7 partial or relative adjectives familiar, similar, abnormal, atypical, sick, different, bad, healthier, worse, better $(\mathrm{M}=$ $.64, \mathrm{SD}=.22$ vs. $\mathrm{M}=.39, \mathrm{SD}=.28$ ), but the difference is not statistically significant. The results of a non-paired t-test are almost but not quite significant $(\mathrm{t}=2.067$; $\mathrm{df}=15$; $\mathrm{P}=.056$ ); the situation worsens upon exclusion of the comparatives.

Table 6 presents of the results of the second type of measurement of the percentage of Google hits with each adjective that are preceded by modifiers characteristic of total adjectives (entirely and perfectly), partial adjectives (slightly and partially), and relative adjectives (very), respectively. The second left column of table 6 presents Google's estimation of the number of counts of each adjective in thousands ('frequency'). The third column presents Google's estimation of frequency of occurrence of each adjective preceded by entirely divided by the adjective's frequency. The subsequent columns present the data for the other modifiers.

Figure 3 illustrates the results of table 6 by presenting the relative size of the scores of partial ('slightly' and 'partially') and total ('perfectly' and 'entirely') modification for each adjective. For example, the preference for partial- as opposed to relative or totalmodification is greatest for the item atypical. ${ }^{21}$

\footnotetext{
Forth, $x$ is more $P$ than $y$ entails that $x$ is $P$ in minimum standard adjectives (iva), that $y$ is not $P$ in maximum standard adjectives (ivb), and neither that $\mathrm{x}$ is $\mathrm{P}$ nor that $\mathrm{y}$ is not $\mathrm{P}$ in relative adjectives (ivc):

(iv)a. The door is more open than the window $\Rightarrow \quad$ The door is open.

b. The door is more closed than the window $\Rightarrow \quad$ The window is not closed.

c. Rod A is longer than Rod B $\quad \neg \quad$ Rod A is long/ Rod B is not long.

${ }^{21}$ The figure does not represent whether relatively many or few counts of atypical are preceded by a modifier at all, whether partial or other.
} 
Table 6: Modifier distribution

The table presents the percent of Google counts (July 2010) in which adjectives are preceded by modifiers indicative of total (entirely and perfectly), partial (slightly and partially), and relative (very) interpretations, respectively. The normalized Totalility index on the rightmost column presents the frequency of total modifiers among hits with either total or partial modification.

\begin{tabular}{|c|c|c|c|c|c|c|c|}
\hline Comparatives & $\begin{array}{c}\text { FREQUENCY } \\
\text { IN THOUSANDS } \\
\end{array}$ & $\begin{array}{c}\text { ENTIRELY } \\
\% \\
\end{array}$ & $\begin{array}{c}\text { PERFECTLY } \\
\% \\
\end{array}$ & $\begin{array}{c}\text { SLIGHTLY } \\
\% \\
\end{array}$ & $\begin{array}{c}\text { PARTIALLY } \\
\% \\
\end{array}$ & $\begin{array}{c}\text { VERY } \\
\% \\
\end{array}$ & $\begin{array}{c}\text { Normalized } \\
\text { Totality \% } \\
\end{array}$ \\
\hline WORSE & 93,600 & 0.01 & 0.00 & 0.35 & 0.00 & 0.13 & 2 \\
\hline BETTER & 826,000 & 0.00 & 0.00 & 0.28 & 0.00 & 0.02 & 3 \\
\hline HEALTHIER & 32,800 & 0.01 & 0.00 & 0.25 & 0.00 & 0.02 & 3 \\
\hline SICKER & 1,100 & 0.00 & 0.00 & 0.18 & 0.00 & 0.50 & 4 \\
\hline Adjectives & $\begin{array}{c}\text { FREQUENCY } \\
\text { IN THOUSANDS }\end{array}$ & $\begin{array}{c}\text { ENTIRELY } \\
\% \\
\end{array}$ & $\begin{array}{c}\text { PERFECTLY } \\
\% \\
\end{array}$ & $\begin{array}{c}\text { SLIGHTLY } \\
\% \\
\end{array}$ & $\begin{array}{c}\text { PARTIALLY } \\
\%\end{array}$ & $\begin{array}{c}\text { VERY } \\
\%\end{array}$ & $\begin{array}{c}\text { Normalized } \\
\text { Totality \% }\end{array}$ \\
\hline ATYPICAL & 5,020 & 0.08 & 0.01 & 0.35 & 0.01 & 0.71 & 19 \\
\hline ABNORMAL & 21,300 & 0.19 & 0.03 & 0.41 & 0.00 & 0.25 & 35 \\
\hline DIFFERENT & 791,000 & 0.63 & 0.01 & 1.02 & 0.00 & 3.26 & 38 \\
\hline SICK & 111,000 & 0.02 & 0.01 & 0.03 & 0.00 & 1.33 & 49 \\
\hline SIMILAR & 665,000 & 0.01 & 0.01 & 0.01 & 0.00 & 2.24 & 50 \\
\hline FAMILIAR & 128,000 & 0.04 & 0.04 & 0.03 & 0.01 & 1.81 & 68 \\
\hline INTELLIGENT & 69,500 & 0.01 & 0.08 & 0.03 & 0.00 & 2.19 & 71 \\
\hline $\mathrm{BAD}$ & 627,000 & 0.01 & 0.02 & 0.01 & 0.00 & 1.90 & 73 \\
\hline UNFAMILIAR & 10,100 & 1.11 & 0.00 & 0.20 & 0.00 & 0.53 & 85 \\
\hline HEALTHY & 172,000 & 0.06 & 0.26 & 0.05 & 0.00 & 1.09 & 87 \\
\hline DISSIMILAR & 3,330 & 3.45 & 0.07 & 0.42 & 0.01 & 2.88 & 89 \\
\hline IDENTICAL & 50,400 & 0.09 & 0.15 & 0.00 & 0.03 & 0.23 & 89 \\
\hline GOOD & $1,720,000$ & 0.00 & 0.11 & 0.01 & 0.00 & 8.55 & 90 \\
\hline TYPICAL & 107,000 & 0.06 & 0.03 & 0.01 & 0.00 & 0.46 & 92 \\
\hline NORMAL & 444,000 & 0.03 & 0.34 & 0.01 & 0.00 & 0.13 & 98 \\
\hline
\end{tabular}

Figure 3: The relative size of the frequency scores of partial ('slightly' and 'partially') and total ('perfectly' and 'entirely') modification in each adjective.

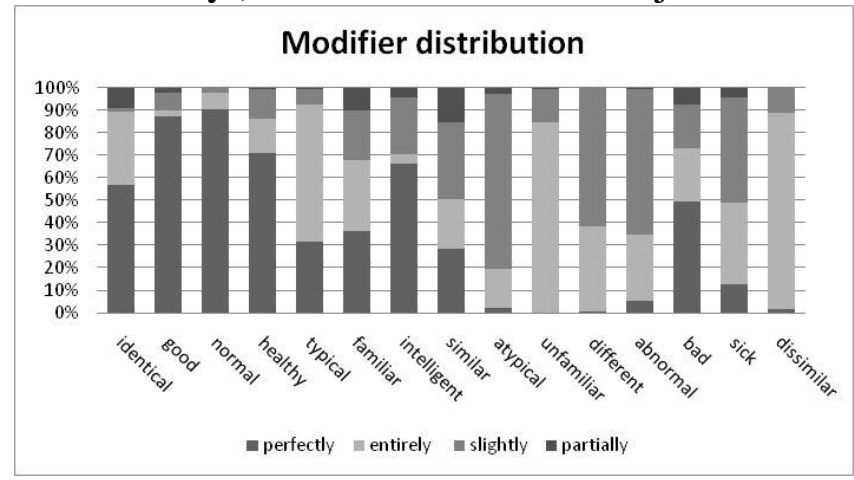

Let an adjective's totality value be the frequency in which it occurs modified by perfectly and entirely, namely, |perfectly $\mathrm{A}|/| \mathrm{A} \mid$ + |entirely $\mathrm{A} / / \mathrm{A} \mid$; this index, arguably, represents the relative frequency of total interpretation in different adjectives. Similarly, let an adjective's partiality value be the frequency in which it occurs modified by slightly and partially - |slightly $\mathrm{A}|/| \mathrm{A}|+|$ partially $\mathrm{A}|/| \mathrm{A} \mid$; this index represents the relative frequency of partial interpretation in different adjectives. A combination of these two values, an adjective's normalized totality, is its totality value divided by the sum of 
its totality and partiality values. This combined index represents the frequency of a total interpretation, given a non-relative (total or partial) interpretation.

In addition, recall that an adjective's conjunctivity value is the frequency of dimension set uses in positive contexts; an adjective's disjunctivity value is the frequency of dimension set uses in negative contexts. A combination of these two values, an adjective's normalized conjunctivity is its conjunctivity value divided by the sum of its conjunctivity and disjunctivity values. This combined index represents the frequency of conjunctive interpretations, given either conjunctive or disjunctive interpretations.

We can now ask whether there is correlation between normalized totality and normalized conjunctivity in non-comparative adjectives.

Including the three comparative adjectives, the correlation between normalized totality and normalized conjunctivity is $r=.308$. Table 6 clearly indicates that the three comparative adjectives are by no means total, regardless of whether they tend more toward a conjunctive or a disjunctive interpretation. This is expected by hypothesis 3, with which our sample is consistent, whereby in comparative adjectives, unlike other adjectives, the conjunctivity and disjunctivity values are not determined by their partial standard type, or by their tendency toward partial modification; rather, their dimensions are integrated via the default operation of the adjectives from which they derive.

However, in non-comparative adjectives, normalized totality and normalized conjunctivity admit a moderate to strong correlation, $\mathrm{cf}$. Figure $4 \mathrm{~A}(\mathrm{r}=.6236, \mathrm{P}<.0129$; the non-parametric Spearman correlation yields $r_{S}=.6964, t=3.5$, df $=13, \mathrm{P}<.004$.)

Figure 4A

Figure 4B

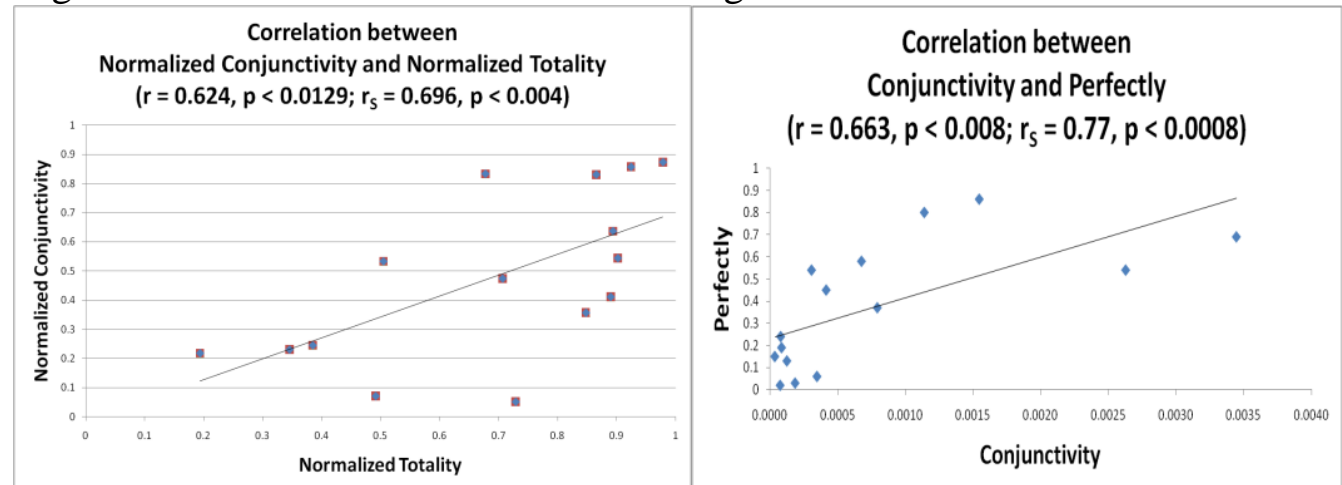

Figure 4A presents a linear correlation between dimension integration (normalized conjunctivity) and standard type (normalized totality), excluding the comparatives $(n=15, r=.6236, p<.0129$; note also that the non-parametric Spearman rank-order correlation yields $r_{S}=.6964, t=3.5, \mathrm{df}=13, \mathrm{p}<.004$.)

Figure 4B presents a linear correlation between conjunctivity vs. frequency of perfectly, excluding the comparatives $\left(\mathrm{n}=15, \mathrm{r}=.663, \mathrm{P}<.008\right.$; also: $\mathrm{r}_{\mathrm{S}}=.77, \mathrm{t}=4.36, \mathrm{P}<.0008$. $)$

This finding supports hypothesis set $4 a-b$, whereby a default standard type is a cue for default dimension integration. The modifier perfectly and the conjunctivity scores are the main contributors to this correlation. As illustrated in Figure 4B, the correlation between conjunctivity and the frequency distribution of perfectly is moderate to strong 
$\left(\mathrm{n}=15, \mathrm{r}=.663, \mathrm{P}<.008 ; \text { Spearman correlation yields } \mathrm{r}_{\mathrm{S}}=.77, \mathrm{t}=4.36, \mathrm{P}<.0008 .\right)^{22}$. Tests of correlations with other modifiers and with disjunctivity did not yield significant results, and were affected by exclusion or inclusion of deviant cases. ${ }^{23}$

\subsubsection{Discussion}

The frequencies of modifiers in Table 6 are based on estimations by Google, which are sometimes not reliable, and they are predictably affected by noise. The modifier very, for example, has additional irrelevant interpretations that can be licensed with nonrelative adjectives or even nouns (as in the very first paper I have published was...) In addition, very sicker, for example, is obviously ungrammatical, but is found in examples such as I'm very sick, very sicker than you (syntactic priming probably plays a role here). Such noise affects the results most for adjectives that co-occur with degree modifiers rarely, i.e. in particular, sicker and other derived comparatives. ${ }^{24}$

That being said, for the most parts, the figures seem to reliably represent English speakers' intuitions. Moreover, the correlations illustrated in Figure 4 support the hypothesis that the modifier perfectly is a cue for default conjunctive dimension integration. If perfectly is also a cue of default standard type, there is a connection between standard type and dimension integration type.

Many other adjectives must be considered. In addition, many modifiers other than those used in this study are indicative of standard type, such as almost, completely and totally. I leave it for the future to test whether taking into account additional modifiers results in better fit, especially ones characterizing negative adjectives, since the main non-comparative outliers are negative adjectives, in particular, bad, sick, dissimilar and unfamiliar. These findings add up to Tribushinina's findings (2009), according to which non-total negative adjectives license maximizers like entirely in a variety of languages.

The connection between dimension integration and standard type only holds to the extent that a given modifier distribution indeed indicates distribution of a given standard type. Classification by judgment tests (Kennedy and McNally 2005), at some parts, differs from classification by modifier-distribution (see also Sauerland and Stateva 2010; Tribushinina 2010b). For example, on the one hand, intuitively, the adjective bad is partial, since, for example, \#the paper is not bad, but it is somewhat bad is odd; in addition, my paper is worse than yours implies that my paper is bad, and does not imply that your paper is not bad; rather to the contrary, it implies that it is bad too. These judgments suggest that bad is partial. On the other hand, intuitively, entirely bad and perfectly bad are grammatical, while slightly bad and somewhat bad are odd. These

\footnotetext{
${ }^{22}$ Similarly, normalized conjunctivity correlates with frequency of co-occurrence with perfectly $(\mathrm{n}=15, \mathrm{r}$ $=.6344, \mathrm{P}<.012$ and $\left.\mathrm{r}_{\mathrm{S}}=.646, \mathrm{t}=3.05, \mathrm{P}<.009\right)$. By contrast a weak negative corralation with disjunctivity does not reach significance $\left(\mathrm{r}=-.235, \mathrm{P}=.4\right.$; is $\left.\mathrm{r}_{\mathrm{S}}=-.08, \mathrm{t}=-.3, \mathrm{P}=.77\right)$.

23 -Entirely $\times$ conjunctivity: $\mathrm{r}=.08, \mathrm{P}<0.78$ (without dissimilar $\mathrm{r}=-.323, \mathrm{P}<.261$ );

-Entirely $\times$ disjunctivity: $\mathrm{r}=.499, \mathrm{P}<.058$ (without dissimilar $\mathrm{r}=-.034, \mathrm{P}=0.9$ );

-Slightly $\times$ conjunctivity: $\mathrm{r}=-.361, \mathrm{P}<.185$ (without different $\mathrm{r}=-0.3, \mathrm{P}<.3$ );

-Slightly $\times$ disjunctivity: $\mathrm{r}=.262, \mathrm{P}<.345$ (without different $\mathrm{r}=.4, \mathrm{P}<.155$ );

-Partially $\times$ conjunctivity: $\mathrm{r}=.469, \mathrm{P}<.0785$ (without identical $\mathrm{r}=.135, \mathrm{P}<0.647$ );

-Partially $\times$ disjunctivity: $\mathrm{r}=.33, \mathrm{P}<.23$ (without identical $\mathrm{r}=.405, \mathrm{P}<.15$ ).

${ }^{24}$ Sicker was excluded from the sample of the study because it rarely co-occurs with except; the data was too scarce to assess frequency of exception phrases operating on dimensions.
} 
judgments are reliably reflected by Google's estimations in that, of these two pairs of modifiers, the former co-occurs with bad more often than the latter. ${ }^{25}$

All considered, it is possible that modifier distribution is affected by a variety of factors that go beyond mere standard type as refleced by judjments, which mainlyy pertain to maximum vs. minimum degrees. One factior may be the frequency of universal vs. existential quantification over parts, or other aspects of interpretation.

An alternative possibility to consider for the future is that in multidimensional adjectives modifier distribution indicates dimension integration, independently of the standard type. This alternative explanation is appealing in that it suggests an account for the existence of groups of near synonyms and antonyms, like identical, similar, different, dissimilar, and excellent, good, bad, terrible. If positive adjectives generally are conjunctive, and negative ones generally are disjunctive, but they may have either type of standard, it is useful to have several near synonyms and near antonyms, which differ in whether their standard tends to be an extremely low point on the given scale (e.g., dissimilar, terrible), an extremely high point (identical, excellent), or some midpoint on the scale, which is relatively low (different, bad) or high (similar, good).

If this alternative possibility is correct, it speaks against the general hypothesis that a default quantificational force is associated uniformly with several aspects of a given adjectival interpretation. Conclusions on this point await future research.

Finally, looking at the likelihood of a relative interpretation as measured by the use of very, we see the following values for the non-comparative mixed adjectives: identical $(0.23 \%)$, similar (2.24\%), good (8.55\%), intelligent (2.19\%), dissimilar (2.88\%), unfamiliar $(0.53 \%)$. The average use of very with the rest of the non-comparative adjectives is $1.32 \%$; hence, 4 out of 6 of the mixed adjectives are far above these values (the exceptions are identical and unfamiliar). We see that with good, the use of very is exceptionally frequent. Good is also very clearly mixed. The comparative of good is rarely used with very, but this is expected. Since it is a comparative, it patterns with good with respect to dimension integration, over and above the fact that it is clearly partial. All considered, $75 \%$ (6 out of 8 ) of the mixed adjectives support hypothesis $3 \mathrm{c}$ in that they are either relatively relative or are comparatives of relatively relative adjectives. Again, many more modifiers other than very are indicative of relative interpretation (e.g., extremely, really, relatively and too, cf. Syrett 2007). I leave it for the future to test whether taking into account additional modifiers results in better fit.

\footnotetext{
${ }^{25}$ Interestingly, perfectly is a better predictor of conjunctivity vs. disjunctivity than entirely. Apparently, perfectly is almost entirely incompatible with negative adjectives, while entirely is perfectly compatible.

While maximizers such as entirely are thought to only combine with total adjectives in English, as observed by Tribushinina $(2009 ; 2010 b)$, in other languages, like Russian, they also combine with relative adjectives, and especially negative ones. Thus, whereas entirely short is flat out ungrammatical in English, its Russian equivalent can be used felicitously to refer to local height minimums. Negative relative adjectives (e.g., korotkij 'short,' dešëvyj 'cheap') are quite frequently modified by maximizers (soveršenno 'totally'/'perfectly', absolûtno 'absolutely,' sovsem 'entirely'/'completely'; polnost' $\hat{u}$ 'fully'). It is plausible, then, that some negative adjectives in English as well are capable of licensing maximizers, which explains the high frequency of entirely with partial negative adjectives like bad and different (the latter is cited by Syrett 2007 among the most frequent adjectives occurring with total modifiers).

Moreover, the scales of these adjectives are intuitively lower-closed (having a minimum), but upper open (lacking a maximum), meaning that licensing of maximizers is unlikely to be explained by virtue of a doubly-closed scale, whereby a maximum exists that does not function as a standard, cf. Kennedy's 2007 account for the felicity of maximizers with the total adjective closed and the partial adjective open.
} 


\section{General discussion}

The reported studies investigate the structure and interpretation of thousands of examples of exception phrases modifying adjectives and nouns, one by one. Because of the difficulty involved in doing so, the sample size, in terms of number and types of adjectives and nouns considered, is limited. It is too small for the results to generalize conclusively. Still, the results are suggestive of interesting generalizations along the lines of the hypotheses in sets 1-4. Thus, the fruitfulness of the experimental method calls for future research into the problems under discussion, with the goal to determine how wide ranging the generalizations are.

The most important results suggest that positive and negative adjectives are different both with respect to conjunctivity and with respect to disjunctivity. More precisely, positive adjectives are more conjunctive than disjunctive, and more conjunctive than their negative antonyms, while negative adjectives are more disjunctive than conjunctive, and they tend to be more disjunctive than their positive antonyms.

Furthermore, in adjectives unmarked for comparison, a moderate to high correlation ( $\mathrm{r}=0.62)$ exists between conjunctivity and totality, as measured by frequency of modification by modifiers like perfectly. Correlation is likely to be improved by taking into account a larger sample of adjectives and relevant degree modifiers, and by systematically considering all possible combinations of antonym polarity and standard type. Another way to improve the precision of the results could be by disambiguating, i.e. separating different interpretations of adjectives. The data from COCA (cf. 2.1) suggest that the force of explicitly used quantifiers over dimensions is a good predictor of the force of implicitly accommodated ones. Google counts with explicit quantification can be examined systematically to support or refute this hypothesis in the future.

Last, but not least, along the way, this study shows that the constraint on the licensing of except in positive polarity contexts should be a bit weaker than one might have thought in advance. The requirement is merely that no existentially quantifying expression blocks the licensing of a possibly implicit universal quantifier. Moreover, since determiners like most appear frequently to suffice for the licensing of except, a question for the future is whether quasi-universal quantification suffices for the licensing of exception phrases, or, alternatively, the interpretation of most involves strictlyuniversal quantification. Clearly, examples like, say, most birds fly, except ostriches can be used to convey all birds fly, except ostriches (likewise, all can be replaced by mostly in I'm all healthy, except for high cholesterol); but can we use such examples if some bird type other then ostriches does not fly, as well? Can existing proposals regarding the semantics of most derive these two putative interpretations compositionally?

\section{A concluding remark}

This paper presented a new, systematic way to uncover rules and strategies that govern the accommodation of implicit operators; the results deepen our understanding of multidimensional adjectives, antonymy and degree modification. Future work should strengthen the empirical basis of the research of implicit operators in the interpretation of adjectives, and aim toward a formulation of a formal semantic-pragmatic theory. 


\section{References}

Ashby, Gregory, F., and Maddox, W. Todd (2005), Human Category Learning, Annual Review of Psychology 56: 149-78.

Büring, Daniel. (2007). Cross-polar nomalies. Proceedings of Semantics and Linguistic Theory (SALT) XVII. Ithaca, NY: CLC Publications.

Cruse, D. A. (1980). Antonyms and gradable complementaries. Perspektiven der Lexikalischen Semantik: Beitrage zum Wuppertaler Semantikkolloquium 2-3: 14-25.

Damon, William, Lerner Richard M., Kuhn Deanna and Siegler Robert S. (eds.) 2006. Handbook of child psychology, volume 2 Cognition, Perception and Language. 6th edition, John Wiley \& Sons.

Davies, Mark. 2010. Corpus of Contemporary American English (http://corpus.byu.edu/coca/). Brigham young university.

Fox, Danny, and Hackl, Martin (2006). The universal density of measurement. Linguistics and Philosophy, 29, 537-586.

Giora, Rachel. (2006). Is negation unique? On the processes and products of phrasal negation. Journal of Pragmatics, 38, 979-980.

Hampton, James. 1995. Testing the prototype theory of concepts. Journal of Memory and Language. 34: 686-708.

Hampton, James. 1998. Similarity based categorization and fuzziness of natural concepts. Cognition 65: 137-165.

Heim, Irene. (2006). Little. Proceedings of Semantics and Linguistic Theory (SALT) $X V I$. Ithaca, NY: CLC Publications.

Heim, Irene. (2008). Decomposing Antonyms? Proceedings of Sinn und Bedeutung 12. 212-225. OSLO.

Hoeksema, Jacob. 1995. The Semantics of Exception Phrases. In Jan van Eijck and Jaap van der Does (eds.) Quantifiers, Logic, and Language, CSLI.

Kamp, Hans. (1975). Two theories about adjectives. In E. L. Keenan (Ed.), Formal semantics of natural language (pp. 123-155). Cambridge: Cambridge University.

Kennedy, Christopher (1999), Projecting the adjective: The Syntax and Semantics of Gradability and Comparison. Garland. NY. (1997 UCSC PhD thesis).

Kennedy, Christopher. (2001). Polar opposition and the ontology of degrees. Linguistics and Philosophy 24(1): 33-70.

Kennedy, Christopher (2007). Vagueness and grammar: The semantics of relative and absolute gradable predicates. Linguistics and Philosophy 30, 1-45.

Kennedy, Christopher and Louise McNally. (2005). Scale structure and. the semantic typology of gradable predicates, Language 81: 345-381.

Klein, Ewan. (1980). A semantics for positive and comparative adjectives. Linguistics and Philosophy, 4, 1-45.

Lakoff, George (1987), Women, Fire and Dangerous Things: What Concepts Reveal about the Mind. Chicago University Press.

Lapata, Mirella and Frank Keller. 2005. Web-based Models for Natural Language Processing. ACM Transactions on Speech and Language Processing 2:1, 1-31.

Lehrer, Adrienne. 1985. Markedness and Antonymy. Journal of Linguistics 21(2 ): 397429. 
Lewis, David, K. (1979), Scorekeeping in a Language Game, Journal of Philosophical Logic 8, 339-59. Reprinted In David K. Lewis (1983), Philosophical Papers 1, 23349, Oxford University Press, NY.

Moltmann, Friederike. 1995. Exception phrases and polyadic quantification, Linguistics and Philosophy 18. 3: 223-280

Murphy, Gregory (2002), The big book of concepts. The MIT Press. Cambridge, MA.

Rett, Jessica. 2007. Antonymy and Evaluativity, Proceedings of Semantics and Linguistic Theory 17. Ithaca, N.Y.: CLC Publications.

Rossedeutcher, A. and Kamp, Hans. (1994). DRS-construction and lexically driven inference. Theoretical Linguistics 20:165.235.

Rotstein, Carmen and Winter, Yoad (2005). 'Total adjectives vs. partial adjectives: Scale structure and higher-order modifiers. Natural Language Semantics 12: 259288.

Sassoon, W. Galit. (2007). Vagueness, Gradability and Typicality, A Comprehensive semantic analysis. Unpublished doctoral Dissertation, Tel Aviv University.

Sassoon, G. W. 2010. The Degree Functions of Negative Adjectives. Natural Language Semantics 18(2): 141-180.

Sassoon, W. Galit (2011a), The double nature of negative antonymy. To appear in the proceedings of Sinn und Bedeutung 16, Utrecht.

Sassoon, W. Galit (2011b), Adjectival vs. nominal categorization processes. MS, ILLC, University of Amsterdam.

Sauerland, Uli and Penka Stateva (2010). Two Types of Vagueness. In Paul Égré and Nathan Klinedinst (Eds.) Vagueness and language use. Palgrave Studies in Pragmatics, Language and Cognition, Palgrave Macmillan.

Solt, Stephanie and Nicole Gotzner, 2010, Expensive, not expensive or cheap? An experimental investigation of vague predicates, Slides presented at the 11th Szklarska Poreba Workshop, Poland.

Syrett, K. (2007). Learning about the Structure of Scales: Adverbial Modifcation and the Acquisition of the Semantics of Gradable Adjectives. Ph.D. thesis, Northwestern University.

Tribushinina, Elena. (2009) The linguistics of zero: A cognitive reference point or a phantom? Folia Linguistica 43(2): 417-461.

Tribushinina, Elena. (2010a). Gradable adjectives in child language. Presented at the meeting of the Vagueness Circle, ILLC, University of Amsterdam, The Netherlands.

Tribushinina, Elena (2010b) Boundedness and relativity: A contrastive study of English and Russian. Languages in Contrast 11.

Weidman, Adar. (1993), Linear Programming using Jensen Inequality, Unpublished Master thesis. The Technion-Israel Institute of Technology. Haifa.

van Rooij, Robert. (2010). 'Vagueness and linguistics.' In G. Ronzitti (ed.), The Vagueness Handbook. Berlin/Heidelberg: Springer.

von-Fintel, Kai. (1993). Exceptive constructions. Natural Language Semantics, 1.2:123148.

Yoon, Youngeun. (1996). Total and partial predicates and the weak and strong interpretations. Natural Language Semantics, 4:217.236. 


\section{Appendix 1: Adjectives and exception phrases, COCA 2010}

Table A: Types of uses of except with some of the 10 adjectives, COCA 2010

\begin{tabular}{|c|c|c|c|}
\hline & P EXCEPT DIM & P EXCEPT PART & P ELSE \\
\hline 1) & $\begin{array}{l}\text { the objects in each of the two groups } \\
\text { were identical except for SIZE. }\end{array}$ & $\begin{array}{l}\text { grammatical readings i and iii } \\
\text { are identical except for THE } \\
\text { READING OF THE VERB } \\
\text { wrecks as transitive (i) or } \\
\text { intransitive ( }\end{array}$ & $\begin{array}{l}\text { The role of the author in the two } \\
\text { works is virtually identical } \\
\text { except IN DEGREE, because } \\
\text { Burgos stops short of admitting } \\
\text { to fictionalizing. }\end{array}$ \\
\hline 2) & $\begin{array}{l}\text { compared the watch with the one he } \\
\text { wore on his wrist. They looked } \\
\text { identical except for the TIME }\end{array}$ & $\begin{array}{l}\text { the end of one section of } \\
\text { concrete and crossed into the } \\
\text { next bay, identical except for } \\
\text { THE FIGURES a dozen feet } \\
\text { away, frozen in front of an } \\
\text { open car }\end{array}$ & $\begin{array}{l}\text { wasn't crazy about the } \\
\text { superheroes or supervillains. } \\
\text { They were boring, ALL } \\
\text { identical except for their } \\
\text { particular gimmicks. }\end{array}$ \\
\hline \multirow[t]{2}{*}{ 3) } & $\begin{array}{l}\text { We found the two services practically } \\
\text { identical except in PRICE }\end{array}$ & $\begin{array}{l}\text { The scenarios were identical } \\
\text { except for THE TWO } \\
\text { MANIPULATED } \\
\text { VARIABLES, the intoxication } \\
\text { level of Chris and the } \\
\text { intoxication level }\end{array}$ & $\begin{array}{l}\text { In fact, EVERYTHING about } \\
\text { these two types of programs is } \\
\text { identical except their use. }\end{array}$ \\
\hline & P EXCEPT DIM & $\begin{array}{l}\text { P ELSE } \\
\text { (explicit quantification/plural) }\end{array}$ & \\
\hline 1) & $\begin{array}{l}\text { the genes had apparently sneaked in, } \\
\text { yielding cells that appeared normal } \\
\text { except for their green glow. }\end{array}$ & $\begin{array}{l}\text { Preoperative cardiopulmonary } \\
\text { function TESTS and blood } \\
\text { oxygen LEVELS were normal } \\
\text { except for a sinus tachycardia } \\
\text { up to } 140 \mathrm{bpm} \text {. }\end{array}$ & $\begin{array}{l}\text { EVERYTHING was pretty } \\
\text { normal except for the fact that } \\
\text { I had a father who was missing. }\end{array}$ \\
\hline 2) & $\begin{array}{l}\text { The morning was almost normal } \\
\text { except for the awkwardness that } \\
\text { seems to be hovering over the city } \\
\text { like a dark rain }\end{array}$ & $\begin{array}{l}\text { ALL IN ALL, I was getting } \\
\text { normal except for girls and my } \\
\text { size: I quit rising at three feet } \\
\text { six. }\end{array}$ & \\
\hline 3) & $\begin{array}{l}\text { On the right side, the middle ear } \\
\text { cavity was normal except for a small } \\
\text { amount of blood in the posterior } \\
\text { epitympanum and mesotympanum, } \\
\text { which was }\end{array}$ & $\begin{array}{l}\text { OPS Normal except for the } \\
\text { radio conversation between the } \\
\text { AC and the Air Traffic } \\
\text { Controller }\end{array}$ & \\
\hline 4) & & & \\
\hline
\end{tabular}

\begin{tabular}{c|l|l|l} 
& P EXCEPT DIM & $\begin{array}{l}\text { P ELSE } \\
\text { (explicit } \\
\text { quantification/plural) }\end{array}$ & P NEG \\
\hline 1) & $\begin{array}{l}\text { The groups were similar except for } \\
\text { SEX, the placebo group having more } \\
\text { boys (table 2). }\end{array}$ & $\begin{array}{l}\text { The Ranges and Means for } \\
\text { ALL OF THE ACTIVITIES } \\
\text { appears very similar except for } \\
\text { Conditioning and Rhythmic } \\
\text { Activities. }\end{array}$ & \\
\hline 2) & $\begin{array}{l}\text { bargaining and faculty salaries, that } \\
\text { is, matching pairs of schools that are } \\
\text { similar except for UNION STATUS. }\end{array}$ & $\begin{array}{l}\text { Percentages of males and } \\
\text { females within STUDENT } \\
\text { CATEGORIES were similar } \\
\text { except for the EBD group, }\end{array}$ & $\begin{array}{l}\text { which had a higher percentage } \\
\text { of males. }\end{array}$
\end{tabular}

\section{P EXCEPT DIM}

P ELSE (quantification over times)

P NEG ELSE (explicit quantification) 


\begin{tabular}{l|l|l|l} 
1) & $\begin{array}{l}\text { But now that I am involved; } \\
\text { it is very different Except } \\
\text { ON SUNDAYS, when I } \\
\text { cheer my heart out. }\end{array}$ & $\begin{array}{l}\text { The Friday night before } \\
\text { Flynn had an abortion was } \\
\text { NO different except } \\
\text { Margaret, who'd lent Flynn } \\
\text { the money, couldn't } \\
\text { concentrate. }\end{array}$ \\
\hline 2) & & $\begin{array}{l}\text { Aside from that he hasn't } \\
\text { changed since I met him. } \\
\text { NOTHING is different } \\
\text { except that he is growing } \\
\text { older, and so am I. }\end{array}$
\end{tabular}

\section{Appendix 2: Adjectives and exception phrases, Google}

Table B: Exception phrases co-occurring with healthy and sick

On tables B in examples of dimension set readings, expressions relating to dimensions are written with capital letters. In other examples ('P ELSE'), expressions are written with capital letters if they explicitly refer to (or trigger accommodation of) a quantifier or of a domain for the exception phrase to operate on (individuals, parts, locations, times, etc.)

\begin{tabular}{|c|c|c|c|c|}
\hline & $\begin{array}{l}\text { HEALTHY } \\
\text { EXCEPT DIM }\end{array}$ & $\begin{array}{l}\text { HEALTHY } \\
\text { ELSE }\end{array}$ & $\begin{array}{l}\text { NOT HEALTHY EXCEPT } \\
\text { DIM }\end{array}$ & NOT HEALTHY ELSE \\
\hline 1. & $\begin{array}{l}\text { people are told that they are } \\
\text { healthy, except for. their } \\
\text { OBESITY. }\end{array}$ & $\begin{array}{l}\text { She has OTHERWISE been } \\
\text { relatively healthy except for } \\
\text { a long history of asthma. }\end{array}$ & $\begin{array}{l}\text { working like a dog this } \\
\text { weekend as I do every } \\
\text { weekend. } 24 \text { hours in } 2 \text { days. } \\
\text { Not healthy, excpt FOR MY } \\
\text { BANK ACCOUNT }\end{array}$ & $\begin{array}{l}\ldots \text { that the infant was not } \\
\text { healthy except [= IN } \\
\text { ADDITION TO] for the } \\
\text { regurgitation or vomiting }\end{array}$ \\
\hline 2. & $\begin{array}{l}\text {...I am a 64-year-old man, } \\
\text { quite healthy except for high } \\
\text { BLOOD PRESSURE, which } \\
\text { was diagnosed last year. My } \\
\text { doctor gave me Hydro-Diuril, } \\
\text { which was only partly ... }\end{array}$ & $\begin{array}{l}\text { I have a } 2 \text { yr old ginger tom } \\
\text { who is PERFECTLY } \\
\text { healthy, except his gums } \\
\text { seem to have dark brown } \\
\text { patches on them? - }\end{array}$ & $\begin{array}{l}\text { confusion is not healthy } \\
\text { except that IT WILL } \\
\text { ULTIMATELY LEAD TO } \\
\text { THE TRUTH }\end{array}$ & $\begin{array}{l}\text { anything above that is } \\
\text { overweight and NOT } \\
\text { HEALTHY. EXCEPT in } \\
\text { a few medical } \\
\text { circumstances, there is } \\
\text { no excuse for being } \\
\text { overweight }\end{array}$ \\
\hline 3. & $\begin{array}{l}\text { I gave a kidney, some years } \\
\text { ago (I'm } 59 \text { and basically } \\
\text { healthy, except for TOO } \\
\text { MUCH FAT, no gall bladder } \\
\text { and colestherol in the liver, a } \\
\text { few things more not ... }\end{array}$ & $\begin{array}{l}\text { She took no medications } \\
\text { and stated that she was } \\
\text { GENERALLY healthy, } \\
\text { except for minor chronic } \\
\text { anemia. She exercised } \\
\text { frequently and denied use } \\
\text { of tobacco or ... }\end{array}$ & $\begin{array}{l}\text { It should be noted that many } \\
\text { affluent neighborhoods, also, } \\
\text { are not healthy, except for } \\
\text { THEIR ECONOMIC } \\
\text { CONDITION. The lack of } \\
\text { community that ... }\end{array}$ & $\begin{array}{l}\text { nearly all estrogen given } \\
\text { in medicine is not } \\
\text { healthy, except IN } \\
\text { CASES WHERE a } \\
\text { woman has had her } \\
\text { ovaries removed }\end{array}$ \\
\hline 4. & $\begin{array}{l}\text { A total of } 54 \text { patients (mean } \\
\text { age } 11.5 \text { years, median } 11 \text {, } \\
\text { standard deviation } \pm 4.52 \text { ) } \\
\text { were healthy except for } \\
\text { NEUROPATHIC BLADDER } \\
\text { due to }\end{array}$ & $\begin{array}{l}\text { The skin over the } \\
\text { encephalocele was BY } \\
\text { AND LARGE healthy, } \\
\text { except FOR A SMALL } \\
\text { AREA in the center where } \\
\text { there was skin erosion. ... }\end{array}$ & & $\begin{array}{l}\text { Although, MOST } \\
\text { VEGETARIANS I know } \\
\text { (and there are a lot in this } \\
\text { area) never seem to look } \\
\text { very healthy, except FOR } \\
\text { THE FEW that regularly } \\
\text { take many vitamin ... }\end{array}$ \\
\hline 5. & $\begin{array}{l}\text { I am healthy except for high } \\
\text { CHOLESTEROL, high } \\
\text { BLOOD PRESSURE, and a } \\
\text { high bmi. }\end{array}$ & $\begin{array}{l}\text { EVERYBODY in the } \\
\text { dining table look healthy } \\
\text { except uncle }\end{array}$ & & $\begin{array}{l}\text { noth healthy, except THE } \\
\text { GREEN TEA PART }\end{array}$ \\
\hline
\end{tabular}




\begin{tabular}{|c|c|c|c|c|}
\hline 6. & $\begin{array}{l}\text { a brother to the proband, was } \\
\text { healthy except for } \\
\text { INFERTILITY; he had had. } \\
\text { three wives, one of whom had } \\
\text { previously borne children }\end{array}$ & $\begin{array}{l}\text { Mental health was not } \\
\text { considered as part of being } \\
\text { healthy except BY A FEW } \\
\text { of the oldest children. }\end{array}$ & & $\begin{array}{l}\text { EVERYTHING on the } \\
\text { menu is yummy but not } \\
\text { healthy, except maybe } \\
\text { the }\end{array}$ \\
\hline 7. & $\begin{array}{l}\text { I'm healthy except for } \\
\text { DIABETES. }\end{array}$ & $\begin{array}{l}\text { A family of four was } \\
\text { healthy, except FOR ONE } \\
\text { SON, who had asthma. }\end{array}$ & & $\begin{array}{l}\text { too much of } \\
\text { ANYTHING is not } \\
\text { healthy. except money }\end{array}$ \\
\hline 8. & $\begin{array}{l}\text { I was } 26 \text { and pretty healthy } \\
\text { except for SOME MILD } \\
\text { ASTHMA. }\end{array}$ & $\begin{array}{l}\text { MOSTLY eating healthy } \\
\text { except FOR ONE DAY A } \\
\text { WEEK WHEN we eat out }\end{array}$ & & $\begin{array}{l}\text { MOST food here is } \\
\text { obviously not healthy, } \\
\text { except for the salads. }\end{array}$ \\
\hline 9. & $\begin{array}{l}\text { I worked at the infamous } \\
\text { "bomb" plant for } 31 \text { years and } \\
\text { am still healthy except for AN } \\
\text { UNRELATED HEART } \\
\text { PROBLEM. }\end{array}$ & $\begin{array}{l}\text { EVERY YEAR he's been } \\
\text { healthy except this pass } \\
\text { year. Vince is incredible if } \\
\text { we pass on Vnce we will } \\
\text { live to regret it. ... }\end{array}$ & $\begin{array}{l}\text { Unless you are a child, it is } \\
\text { NOBODY else's job to keep } \\
\text { you healthy except yours. }\end{array}$ & $\begin{array}{l}\text { There's NOTHING I eat } \\
\text { that's not } \\
\text { healthy...except maybe } \\
\text { beer }\end{array}$ \\
\hline
\end{tabular}

\begin{tabular}{|c|c|c|c|c|}
\hline & $\begin{array}{l}\text { SICK } \\
\text { EXCEPT DIM } \\
\end{array}$ & $\begin{array}{l}\text { SICK } \\
\text { ELSE }\end{array}$ & \begin{tabular}{|l} 
NOT SICK \\
EXCEPT DIM \\
\end{tabular} & $\begin{array}{l}\text { NOT SICK } \\
\text { ELSE } \\
\end{array}$ \\
\hline 1. & $\begin{array}{l}\text { I think its sick, except A } \\
\text { FEW THINGS. I have } \\
\text { never heard of those subs, } \\
\text { id swap em out for JL } \\
\text { Subs and Amps..id get rid } \\
\text { of the body kit on the } \\
\text { front, and maybe change } \\
\text { the rims.. but if it was } \\
\text { cheap for me to buy that id } \\
\text { definitely buy it }\end{array}$ & $\begin{array}{l}\text { he said Edna was home and } \\
\text { they were ALL sick except } \\
\text { HER AND DAN. }\end{array}$ & $\begin{array}{l}\text { Haven't really been sick } \\
\text { except maybe A COLD }\end{array}$ & $\begin{array}{l}\text { We were all very seasick } \\
\text { indeed for the first two } \\
\text { days but after that NONE } \\
\text { OF US WERE AT ALL } \\
\text { sick, except Gen. }\end{array}$ \\
\hline 2. & & $\begin{array}{l}\text { There's been so much bad } \\
\text { news on the health care front } \\
\text { for working Americans that it } \\
\text { makes us SICK. EXCEPT, if } \\
\text { you do get sick you probably } \\
\text { can't afford it. }\end{array}$ & $\begin{array}{l}\text { He has not really been } \\
\text { seriously sick except for HIS } \\
\text { EARS. The ears problem } \\
\text { runs in both my family and } \\
\text { my husbands. }\end{array}$ & $\begin{array}{l}\text { I don't mean to brag, but I } \\
\text { just don't USUALLY get } \\
\text { real sick. Except last year } \\
\text { I had pneumonia right } \\
\text { about ... }\end{array}$ \\
\hline 3. & & $\begin{array}{l}\text { On Thursday I was off SICK. } \\
\text { EXCEPT I was only half sick } \\
\text { and the rest was tiredness. }\end{array}$ & $\begin{array}{l}\text { physicall, I am not sick } \\
\text { (except A COLD) }\end{array}$ & $\begin{array}{l}\text { I NEVER got sick except } \\
\text { for maybe a brief cold } \\
\text { each fall and spring. }\end{array}$ \\
\hline 4. & & $\begin{array}{l}\text { The process is exactly the } \\
\text { SAME when I project my guilt } \\
\text { onto my body and get sick, } \\
\text { EXCEPT we call it sickness } \\
\text { instead of anger. }\end{array}$ & $\begin{array}{l}\text { not sick, except my PAIN } \\
\text { WITH THE LASHES }\end{array}$ & $\begin{array}{l}\text { I HARDLY get sick } \\
\text { (EXCEPT THESE } \\
\text { MONTHS that I'm } \\
\text { pregnant) }\end{array}$ \\
\hline 5. & & $\begin{array}{l}\text { If this one comes a knockin', } \\
\text { your body has never seen it } \\
\text { before, it cannot defend you, } \\
\text { and you will get SICK. } \\
\text { EXCEPT in this case, this one } \\
\text { is bad. ... }\end{array}$ & $\begin{array}{l}\text { The affected dog is not sick, } \\
\text { except for THE COUGH }\end{array}$ & $\begin{array}{l}\text { Sick children make as big } \\
\text { gains as the not sick } \\
\text { except AT AGE } 12 \text { and } \\
\text { over }\end{array}$ \\
\hline 6. & & $\begin{array}{l}\text { We're ALL Sick....Except } \\
\text { Jarrod }\end{array}$ & & $\begin{array}{l}\text { They show NO SIGNS of } \\
\text { being sick, except for this } \\
\text { throwing up business. }\end{array}$ \\
\hline 7. & & & & $\begin{array}{l}\text { He is not sick except } \\
\text { WHEN he is sick }\end{array}$ \\
\hline
\end{tabular}

